Chapter 9

\title{
Alzheimer's Disease: From Animal Models to the Human Syndrome
}

Erika Orta-Salazar, Isaac Vargas-Rodríguez,

Susana A Castro-Chavira,

Alfredo I. Feria-Velasco and Sofía Díaz-Cintra

Additional information is available at the end of the chapter

http://dx.doi.org/10.5772/64619

\begin{abstract}
Some animal models, genetically modified (such as murine) and sporadic (as others species), enable the study of the origin of specific lesions observed in human neurodegenerative diseases. In particular, Alzheimer's disease (AD) models have been designed to test the hypothesis that certain lesions are associated with functional and morphological changes beginning with memory loss and impairment in activities of daily life. This review compares and evaluates the phenotypes of different $\mathrm{AD}$ animal models, on the basis of the specific objectives of each study, with the purpose of encompassing their contributions to the comprehension of the AD signs and symptoms in humans. All these models contribute to the comprehension of the human $\mathrm{AD}$ mechanisms regarding the heterogeneity of $\mathrm{AD}$ phenotypes: the overlap between $\mathrm{AD}$ and age-related changes, the variability of $\mathrm{AD}$ onset (early or late), the probable reactiveness of amyloid- $\beta$ and tau proteins, the scarcity of senile plaques and/or neurofibrillary tangles in some AD cases, the spatial correlation of the pathology and cerebral blood vessels, and the immunological responses (microglial aging) and synaptopathy. Altogether, these considerations may contribute to find therapies to treat and prevent this disease.
\end{abstract}

Keywords: Alzheimer's disease, nutritional risk, murine, human, genetic Alzheimer's disease, sporadic Alzheimer's disease 


\section{Introduction}

Alzheimer's disease (AD) is one of the major progressive and irreversible neurodegenerative diseases associated with aging [1]. The first case was identified by Dr. Alois Alzheimer in 1901 who presented the clinical and neuropathological characteristics of this disease on November 3, 1906 at the 37th meeting of the Society of Southwest German Psychiatrists in Tübingen, Germany [2]. AD is a progressively degenerative disease that destroys the patient's functional capacity and is the primary cause for loss of functional capacity among the elderly in developed countries [3]. AD accounts for $60-80 \%$ of all dementia cases, as described in the Organisation for Economic Cooperation and Development (OECD) report. The number of people worldwide living with AD was estimated at between 27 million and 36 million in 2016 [4, 5]. AD symptoms worsen over time at a variable rate; on average; AD patients live between 4 and 8 years after diagnosis, but they could live until 20 years, depending on various factors. Once installed, three main stages of pathological progression of AD have been defined, namely early, middle and late.

In the early stage, a person may have memory lapses, such as forgetting familiar words or names, losing or misplacing a valuable object, or being unable to plan or organize. The middle stage is the longest and can last many years. The person with middle stage AD may confuse words, become easily frustrated or angry, and has increased difficulty expressing thoughts and performing routine tasks. In late stage or severe dementia, the person loses the ability to respond to the environment, to carry on a conversation and, eventually, to control movement; memory and cognitive skills continue to worsen, personality changes may occur and individuals need extensive help with daily activities [5]. According to the age of onset, AD can be classified as: early-onset or familial AD accounting for only 5-10\% of AD cases, or late-onset or sporadic $\mathrm{AD}$ accounting for the rest of the $\mathrm{AD}$ cases. Familial $\mathrm{AD}$ is associated with mutations in the genes for presenilin (PS) 1 and 2 and/or amyloid precursor protein (APP); its symptoms appear at 30-50 years of age, whereas the majority of sporadic cases develop after age $65[6]$.

$\mathrm{AD}$ is a multifactorial disease that is a pathologically and etiologically complex. There are a few causative genes which have been linked to the relatively small proportion of patients with early-onset familial AD [7]. The molecular analysis of families with early-onset AD has made it possible to identify mutations in genes associated with the disease: APP, PS 1 and PS 2, and the mean onset age is 45. Mutations in Apolipoprotein E $\varepsilon 4$ (Apo E ع4) genes are present in 15$20 \%$ of AD cases appearing after 65 years of age. Three additional genes.

There are numerous hypotheses to explain the appearance of sporadic AD, such as head trauma, neuroinflammation, poor dietary habits and the lack of exercise, but the cause is still unknown $[8,9]$. A possible explanation is that the abundant knowledge of AD biochemistry has not yet been well integrated into the cellular context of brain [10].

In order to elucidate the AD etiology, animal models that have genetic mutations linked to familial $\mathrm{AD}$ and show the same disease progression pattern have been developed. These models are either based on: (1) the overexpression of APP and secretases [11, 12]; (2) mutated $\mathrm{APP}[13,14]$; or (3) the overexpression of human APP (hAPP) together with mutated forms of 
PS [15]. Notwithstanding these mutations, such mouse models rarely develop neurofibrillary tangles (NFTs). To simulate tau pathology, a microtubule-associated protein tau (MAPT) mutation associated with frontotemporal dementia is included in the 3xTg-AD mouse, in which the expression of hAPP and mutated forms of PS and tau are combined [16, 17]. Currently, at least 11 rodent models that exhibit $A D$ characteristics, such as $A \beta$ accumulation, tau pathology, neuronal loss and pathophysiology of glial cells, are being studied $[6,18]$.

\section{Methods}

For the AD definition, relevant representative book chapters, journal articles and a web page were selected aiming to first summarize the basics of well-established knowledge on Alzheimer's disease that included its biochemical, neuropathological and physiological features. Then, a literature search with the computerized PubMed data base was conducted in February, 2016 with no limit of date. We used the following search terms: (Malnutrition AND Senescence), (Malnutrition AND Alzheimer), and (Senescence). Then, relevant references cited in papers found via this search were reviewed. Studies were selected if they either provided updated information on the AD basics or regarding the biological mechanisms underlying Alzheimer's disease. Case studies were excluded. A total of 170 journal articles, four book chapters and a web page were selected.

\section{Histopathological brain changes in AD}

Autopsy studies examining the incidence of neuropathological lesions and clinical symptoms reveal that $\mathrm{AD}$ often occurs in conjunction with other pathologies, specifically, vascular and Lewy body dementias. The overlap of pathologies suggests the existence of common pathophysiological mechanisms [19].

In AD brains, many cellular and molecular changes coincide with changes in the proteins and genes implicated. The two primary lesions associated with AD are NFTs and the senile plaques first described by Alois Alzheimer. Graeber and co-workers explained in 1998 that the tissue sections of cerebral cortex from Auguste D had numerous NFTs and many amyloid plaques, especially in the upper cortical layer of the brain [20]. In this tissue, NFTs can be seen as accumulations of abnormally phosphorylated tau protein within the perikaryal cytoplasm of cortical neurons, and senile plaques consist of a central core of amyloid- $\beta(A \beta)$, a 4-kD peptide, surrounded by abnormally configured neuronal processes or neurites; the neurites are localized similarly in animal models such as the PDAPP first model, which develops plaques and cognitive deficits similar to those in humans [13].

These histopathological features start in the temporal lobe and extend to the Meynert nucleus that projects to the hippocampus and to the frontal, parietal and occipital cortices, all of which have important roles in the control of cognitive functions; gradually, these lesions destroy a person's memory and ability to learn, to reason, to communicate and to carry out daily activities 
[21, 22]. The first histopathological lesion is the intracellular NFT, which consists largely of twisted, hyperphosphorylated filaments of the microtubule-associated protein tau. The second lesion type is the extracellular plaque of differently sized, small amyloid peptides called A $\beta$ that are derived via sequential proteolytic cleavages of APP [23]. The two types of lesions seem to form independently, with tangles appearing first [24]. Affected regions typically exhibit synaptic and neuronal loss, with cholinergic and glutamatergic neurons being the most affected [25], as well as inflammation, gliosis, oxidative stress and neuronal dystrophy [8].

\subsection{Brain atrophy and traumatic brain injury}

New technologies based on structural and functional neuroimaging and on the biochemical analysis of cerebrospinal fluid have established interesting correlates of intracerebral amyloidosis in individuals with mild, pre-dementia symptoms.

Whole brain volume changes are used as surrogate markers for AD neuropathology in clinical studies; the extent to which these changes can be attributed to pathological features of AD in the aging brain may be established using other signs of brain atrophy in patients showing cognitive impairment [26]. The relationship between pathology and brain atrophy is not simple and linear; neither is the distinction between normal aging and the disease, which is a complicated issue. Aging, dementia diagnosis and AD pathologies closely correlate with enlargement of the brain ventricles but not with reduced total brain volume. Ventricle enlargement may be a response to various conditions and reflect changes in both white and gray matter of the brain, and may be related to cerebrovascular disease and AD. Clinically, brain atrophy in AD patients precedes symptoms. Researchers have proposed using brain atrophy as a surrogate marker for pathology in clinical trials and longitudinal studies. For example, decreased hippocampal volume is considered an acceptable marker in people with mild cognitive impairment (MCI) and at early stages of AD.

It is well established that $\mathrm{AD}$ leads to nerve cell death and tissue loss throughout the brain. As more neurons die, more brain regions are affected and over time, the brain shrinks dramatically leading to functional impairment. The atrophy pattern involves white matter and largely spares the isocortex and hippocampus, which is different from that reported in AD patients [27]. The atrophy of the medial temporal lobe, including the entorhinal cortex, amygdala and hippocampus, is closely related to impairment for forming new memories. The hippocampus in AD patients may lose $3-4 \%$ of its volume in a year, whereas average loss in a normal brain is less than $1 \%$. Thus, these hippocampal alterations are one of the best-established signs of AD. Furthermore, the hippocampus is more susceptible to reduced blood flow, which occurs in cortical amyloid angiopathy.

Some studies evaluating brain atrophy in the transgenic PDAPP mouse model found a reduction in hippocampal volume and severe atrophy or agenesis of fiber tracts, fornix and corpus callosum [28-30]. ApoE $\varepsilon 4$ is associated with increased risk of sporadic AD and of conversion from mild cognitive impairment to AD. ApoE $\varepsilon 4$ also plays an important role in brain atrophy and memory impairment by modulating amyloid production and deposition [31]. 
Microglia is the innate immune cell in the brain that, as a result of brain injury like infection or traumatic injury, produces cytokines and may remain primed in a state where a second stimulus produces an exaggerated activation (hyper-reactivity). This response may be triggered by traumatic brain injury, infection or aging [32, 33], which are risk factors for developing AD. Hyper-activated microglia is importantly involved in this process [33-35].

\subsection{Neuronal and synaptic loss}

Extracellular accumulation of $A \beta$ protein and intracellular accumulation of tau in brain tissues have been described in animal models of $\mathrm{AD}$, as well as in some mechanical stress-based diseases with different mechanisms, such as traumatic brain injury, arterial hypertension and normal pressure hydrocephalus.

Numerous studies dealing with AD have shown evidence for synaptic dysfunction, which correlates with cognitive decline along with an abundance of plaques or tangles [36]. Synapse abnormalities in AD brain tissue were first described by Gonatas and colleagues [37]. Quantitative ultrastructural and immunohistochemical postmortem studies of brain samples from patients with MCI to early-mild AD confirmed previous results that synapse loss was an early structural finding that correlated with AD severity. These studies showed a marked loss of synaptic proteins, such as synaptophysin, SV2 and p65, in the brains of AD patients [38-41]. Numerous factors have been associated with increased risk of AD: diabetes, hypertension, smoking, obesity and dyslipidemia [3].

Dysfunction of synaptic communication in cortical and hippocampal networks has been suggested as one of the neuropathological hallmarks of the early stages of AD and has been increasingly referred to as a "synaptopathy", in which the soluble oligomeric A $\beta$ peptide plays a pivotal role in disrupting synaptic function and, thus, in neuronal network activity [42, 43]. In addition, high levels of soluble $\mathrm{A} \beta$ oligomers show a strong correlation with synaptic dysfunction, which contributes to neurodegeneration. This reflects the loss or damage to synapses that occurs as the disease progresses, which in turn produces functional degeneration of specific neuronal circuits and consequent aberrant activity in neural networks; however, the exact mechanisms are still unknown. One possibility is the immediate-early gene Arc/Arg3.1 (early-expression activity-regulated cytoskeletal gene, here referred to as Arc), one of the genes known to be vital for memory consolidation and synaptic plasticity. Also, the mapping of Arc expression patterns in brain networks has been extensively used as a marker of memoryrelevant neuronal activity history. A recent study by Morin et al. proposes that in 3xTg-AD mice, intraneuronal $A \beta$ expression in the hippocampus could increase unspecific neuronal activation and subsequent Arc protein expression, which might impair further memorystabilizing processes [44]. Understanding the link between intracellular A $\beta$ and Arc/Arg3.1 protein function should help disentangle the molecular and cellular mechanisms underlying episodic memory deficits during the early phases of AD and could clarify the role of disrupted hippocampal excitability in memory retrieval deficits occurring in early-stage AD-like pathology. 


\subsection{Synaptopathy}

Activated Arc/Arg3.1 is targeted to the post-synaptic density of synaptically active dendritic spines where it associates with polysomes. Arc interacts with endophilin $2 / 3$ and dynamin, contributing to $\alpha$-amino-3-hydroxyl-5-methyl-4-isoxazole-propionate (AMPA) type glutamate receptor (AMPAR) modulation by enhancing receptor endocytosis. The Arc-endosome also traffics APP and physically associates with PS 1, thereby increasing the amount of activitydependent $A \beta$ [45]. This may be a positive feedback mechanism in which removal of the AMPAR from the synapse will produce a significant loss of dendritic spines and synaptic activity, resulting in synaptic failure similar to that observed in AD. Activity of the N-methyl$\mathrm{D}$-aspartate receptor (NMDAR) in the hippocampus is also known to be crucial for long-term spatial memory formation and to play a role in AD pathogenesis. The NMDAR is localized at synaptic and extra-synaptic sites where it has diverse functions, from modulating memory strength to neurotoxicity and neuroprotection, and one of the components of the NMDARassociated signaling complex is Arc/Arg3.1. Other postsynaptic elements are the lipid rafts (subdomains of the plasma membrane that contain high concentrations of cholesterol and glycosphingolipids), which are involved in cell signaling and with the NMDAR complex. Thus, physiological and pathological events such as ischemia and spatial learning can induce movements of NMDAR signaling complexes between the postsynaptic density and lipid raft subdomains. Synaptopathy and lipid raft disruption may be related to the onset of episodic memory deficits during the early stages of AD [46-48]. In order to analyze this possibility, studies have been initiated to determine the content of NMDA and AMPA receptors as well as Arc/Arg3.1 levels in the lipid raft microdomains of the 3xTg-AD murine model of AD at the pre-plaque stage and to understand perturbations in neurons, which may help to explain the synaptic plasticity deficits and long-term memory impairments observed in AD models.

\section{Proteins in the pathophysiology of AD}

\subsection{The amyloid precursor protein (APP)}

The APP is a type 1 transmembrane glycoprotein of $110-130 \mathrm{kDa}$, one of the most abundant proteins in the central nervous system (CNS), and is cut by $\alpha$-secretase within the sequence of amino acids that comprise the $\mathrm{A} \beta$ peptide, precluding formation of amyloid peptides [49]. In the amyloidogenic pathway, APP is cleaved instead by $\beta$-secretase, releasing a smaller $\mathrm{N}$ terminal fragment (sAPP $\beta$ ) and a longer C-terminal fragment (C99) that contains the full amyloidogenic sequence of amino acids. A further cleavage of APP by $\gamma$-secretase yields the $\mathrm{A} \beta$ peptide. In brain, there is an equilibrium between $\mathrm{A} \beta$ peptide production and its clearance [50]. How $A \beta$ is removed from the brain is not entirely clear, but is mediated by two proteins: apolipoprotein E (APOE) and the insulin-degrading enzyme (IDE) that may inhibit its aggregation [51]. Disadvantageous genetic polymorphisms (such as the $\varepsilon 4$ allele of APOE) and pathological conditions related to abnormal IDE homeostasis (e.g., diabetes mellitus) that may favor the amyloidogenic cleavage of APP and/or decrease A $\beta$ clearance from the brain will 
therefore facilitate $A \beta$ accumulation in neural tissues and the downstream effects of the amyloid cascade [52].

\subsection{Deposition of $A \beta$}

$\mathrm{A} \beta$ is produced by endoproteolysis, post-translational processing of the amyloid precursor protein (APP), which is achieved by the sequential cleavage of APP by groups of enzymes or

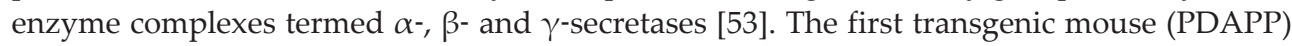
model that developed amyloid plaque pathology was generated by Games and colleagues to express human APP containing mutations associated with early-onset AD; results obtained in these mice support a primary role for $\mathrm{APP} / \mathrm{A} \beta$ in the genesis of $\mathrm{AD}$ and show they could provide a preclinical model for testing therapeutic drugs [13]. Since then, other mouse models have been created that recapitulate all aspects of AD including processing of the APP. However, not all APP transgenic mice have cognitive impairment, cellular loss and other AD characteristics, and they fail to replicate the full human disease. Some models actually confirm that the reduction of $A \beta$ is insufficient to rescue memory function once downstream processes are underway. Conversely, other studies in mice predict that immunization against Abfix might prevent cognitive decline if administered early enough [54]. Also, Schenk et al. [55] studied transgenic mouse models and reported that their active immunization alleviated the burden of amyloid plaque, suggesting a potential therapeutic strategy [56].

Brain injury is reported to accelerate $A \beta$ deposition and exacerbate Alzheimer's disease associated with impairment of cognition prior to the emergence of $A \beta$ plaques. However, the relationships between $A \beta$ levels ( $A \beta 40, A \beta 42$, or the ratio of $A \beta 42$ to $A \beta 40$ ), gender, age and cognitive function were measured in five mouse models (Tg2576, APP, PS 1, APP(OSK)-Tg, $3 \times T g-A D)$, see reference [57]. They used behavior tests such as escape latency times in the Morris water maze or exploratory preference percentage in the novel object recognition test. $\mathrm{Tg} 2576$ mice, overexpressing human $\mathrm{APP}_{695}$ concentration six times greater than that of normal mouse APP levels, show higher levels of $A \beta 40$ and $A \beta 42$ and $A \beta$ deposits that begin at 9 months of age [58]. The APP models express hAPPSw and APP751 isoforms under the control of the murine Thy1 promoter. As a result, this mouse exhibits levels of human APP seven times greater than that of wild-type mice, and its $A \beta$ plaques begin at 6 months of age. The $\mathrm{APP}(\mathrm{OSK})-\mathrm{Tg}$ mouse expresses APP harboring the Osaka (E693) mutation, and it exhibits intraneuronal A $\beta$ oligomers and memory impairment from 8 months of age. The PS 1 model expresses human PS with the mutation M146L or M146V via the PDGF- $\beta$ promoter and higher levels of endogenous mouse A $\beta 1-42 / 43$ [59]. The 3xTg-AD, triple-transgenic model exhibits both $\mathrm{A} \beta$ and tau pathologies and mimics human $\mathrm{AD}[60]$. Thus, the possible role of $\mathrm{A} \beta$ in $\mathrm{AD}$ cognitive decline needs to be further investigated, fueled by other possible hypotheses and explanations [57].

\subsection{Apolipoprotein E}

Genetic association studies reveal that several genes such as ApoE are associated with multiple age-related disorders, indicating that these genes could play a crucial role in their causation. The e 4 allele of the apolipoprotein $\mathrm{E}$ (ApoE) gene is the best-known genetic risk factor for AD, 
because it has been suggested to affect both $\mathrm{A} \beta$ and NFT pathology in AD. ApoE is a 34-kDa lipid-binding protein that functions in the transport of triglycerides and cholesterol in multiple tissues by interacting with lipoprotein receptors on target cells; these functions are particularly critical for the central nervous system where ApoE transport of cholesterol is important for the maintenance of myelin and neuronal membranes [60]. Polymorphism of the ApoE gene has been implicated in many chronic cardiovascular (myocardial infarction, hypertension, coronary heart) and neuronal diseases. The ApoE $\varepsilon 4$ genotype not only is a risk factor for cardiovascular disease but also it combines synergistically with age, atherosclerosis, peripheral vascular disease or type-2 diabetes to increase the risk of AD [62-66].

The ApoE gene is expressed most highly in the liver and brain; genome-wide association studies have confirmed the $\varepsilon 4$ allele of ApoE as the strongest genetic risk factor for $\mathrm{AD}$ $[67,68]$, because over $60 \%$ of persons with $\mathrm{AD}$ harbor at least one ApoE- $\varepsilon 4$ allele, and recent data indicate complex interactions between age, ApoE genotype and gender [61]. In reference [69], Dowell et al. used NMR to study two age groups: a young group (average age, 21 years) and a mid-age group (average age, 50 years); they reported that there are regional white matter brain volume and cortical thickness differences between genotype groups at each age. They raised the possibility that an over-engagement with these regions by e4+ individuals in youth may have a neurogenic effect that is observable later in life. According to a genome-wide association study of cerebrospinal fluid (CSF) from AD subjects, several single nucleotide polymorphisms (SNPs) in the ApoE gene region of the brain were also associated with phosphorylated tau ( $p$ tau) elevated levels in the CSF. When cerebrospinal fluid levels of A $\beta$ 1-42 were analyzed together with tau/ $\mathrm{p}$ tau, a significant correlation was found with SNPs of the ApoE gene. ApoE is also a crucial regulator of the innate immune system, which promotes pro-inflammatory responses that could exacerbate AD pathogenesis [70].

In 2002, Colton et al. demonstrated that ApoE regulates the production of nitric oxide (NO), a critical cytoactive factor released by active macrophages. Thus, due to greater NO production, ApoE4 carriers characteristically have high levels of oxidative/nitrosative stress and a higher incidence of $\mathrm{AD}$, a mechanism that explains the genetic association between ApoE4 and human diseases [71].

\subsection{Tau accumulation}

Besides the accumulation of soluble and toxic $A \beta$-aggregates, tau accumulation causes oxidative stress and mitochondrial dysfunction, and it is linked to the initiation of the tau cascade. The tauopathies are a group of degenerative diseases with histopathology characterized by filamentary inclusions composed of tau protein in neurons (NFT pathology). These are abundant in many neurodegenerative diseases, including AD, Pick's disease, argyrophilic grain disease and frontotemporal dementia with parkinsonism linked to chromosome 17 (FTDP-17) [72]. In AD, the presence of neurofibrillary tangles (NFT) composed of tau is prominent, and their density correlates with neuronal loss and clinical severity [72, 74]. Dystrophic neurites are all sites of accumulation of pathological paired helical filaments (PHFs) that appear to be central to neurofibrillary degeneration of neuropathology and that contain 
(the microtubule-associated protein) tau as an integral structural component [75-78]. Also, tau processing in $\mathrm{AD}$, leading to the formation of paired helical filaments, is driven by aggregation and polymerization, and appears to be associated with abnormal phosphorylation and truncation processes [79]. Mouse models expressing the P301L mutation causing neurofibrillary degeneration have been generated to study neurofibrillary pathologies [80]; and this mutation facilitates the development in transgenic mice of tauopathies [81-83] that recapitulate human tauopathies [83]; these mice provided the opportunity to test experimentally whether the distribution or timing of neurofibrillary pathology is influenced by the pathogenic mutations that cause AD. However, the physiology of tau protein is different in adult mice and humans; because mouse brain contains only isoforms like $4 \mathrm{R}$, while in normal adult human there is a balance between $3 \mathrm{R}$ and $4 \mathrm{R}$ isoforms [85].

There is a clear link between type 2 diabetes mellitus and AD, and the use of antidiabetic drugs such as metformin has been proposed as a potential therapy for AD. There is also experimental evidence that metformin may have beneficial effects on cognition [86]. However, it remains unknown whether, in the absence of insulin resistance or diabetes, chronic treatment with metformin ameliorates tau pathology and behavioral performance in a transgenic model of neurodegenerative tauopathy in vivo. A recent study by Barini et al. shows how metformin modulates tau pathology in vivo. In P301S mice, they found similar levels of tau and ptau in the cortex and hippocampus with or without metformin, but metformin enhanced hyperactive behavior in the open field test. Due to dual actions on tau phosphorylation and aggregation, metformin may unpredictably impact the development of tauopathy in elderly diabetic patients at risk for $\mathrm{AD}[87]$.

In order to elucidate the molecular mechanisms underlying the post-translational modifications of $A \beta$ and tau, several transgenic mouse models have been developed. One of these models is the $3 \mathrm{xTg}-\mathrm{AD}$ transgenic mouse, carrying three transgenes encoding the APPSWE, S1M146V and TauP301L proteins. Ontiveros-Torres et al. reported the hippocampal accumulation of fibrillar $\mathrm{A} \beta$ as a function of age and hyperphosphorylation patterns of TauP301L at both its $\mathrm{N}$ - and C-termini: the expression of activated protein kinases and mediators of inflammation was monitored from 3 to 28 months as well. These authors reported that the accumulation of $\mathrm{A} \beta$ oligomers results in an inflammatory environment that upregulates kinases involved in hyperphosphorylation of the TauP301L polypeptide. The 3xTg-AD mouse is an excellent model for further studying pathological modifications of key factors in AD [88].

\section{Hypotheses explaining AD}

\subsection{Developmental origins of health and adult disease in dementia}

Today, an increasing number of epidemiological, clinical and experimental studies suggest an association between toxicant and drug exposure during the perinatal period and the development of metabolic-related diseases and neurotoxicity later in life. A study called 'The developmental origins of health and adult disease' (DOHaD) addressed fundamental issues in the emerging areas of lifetime neurotoxicity testing, differential vulnerable periods of 
exposure, non-monotonic dose-response effects and neurotoxic risk assessment. Neurotoxicity during central nervous system development results in permanent changes.

The DOHaD hypothesis proposes an association of early fetal environment with adult size, later ischemic heart disease, hypertension, metabolism, diabetes and insulin resistance, which are risk factors for dementia, obesity and deficits in behavior and learning [89-91]. A $\beta$-derived diffusible ligands (ADDL) also contribute to insulin deficits and insulin resistance in the brain of AD patients, and ADDL levels can be used to diagnose AD [92].

The brain of patients with AD has deficits in cerebral glucose utilization due to insulin/IGF resistance associated with increased oxidative stress, DNA damage, reactive oxygen species and mitochondrial dysfunction. The consequences of insulin and IGF resistance in the brain compromise neuronal survival, energy production, gene expression, and cerebral plasticity [93]. Thus, inhibition of insulin/IGF signaling mediates AD neurodegeneration by an increase in activity of kinases which phosphorylate tau; accumulation of $\mathrm{A} \beta \mathrm{PP}-\mathrm{A} \beta$; mitochondrial dysfunction; generation of reactive oxygen and nitrogen species, oxidative and endoplasmic reticulum stress, and signaling through pro-inflammatory and pro-apoptotic cascades $[93,94]$.

Since Hoyer [95] proposed that the deficits in cerebral glucose utilization and energy metabolism worsen with progression in cognitive impairment. In addition, Steen et al. proposed that chronic deficits in insulin signaling mediate the pathogenesis of AD [96]. Additionally, AD could be regarded as a brain disorder that has composite features of type 1 (insulin deficiency) and type 2 (insulin resistance) diabetes. Thus, AD could be referred to as "type 3 diabetes", because both molecular and biochemical consequence overlap with type 1 and type 2 diabetes $[94,97]$. Recently, experimental studies consider that glucose hypometabolism is an early and persistent sign of AD because brains present features of impaired insulin signaling, a model using intracerebroventricular streptozotocin injections (icv STZ model) to generate sporadic $\mathrm{AD}$ that emulates the $\mathrm{AD}$ characteristics of $\mathrm{A} \beta$ deposits on the wall of meningeal and cortical blood vessels, mitochondrial abnormalities and oxidative stress [98].

\subsection{Mitochondria, aging and $A D$}

A major risk factor in patients who progress to dementia is aging, which is characterized by defects in energy metabolism and mitochondrial function. Mitochondrial dysfunction is a hallmark of aging, and it plays a central role not only in Alzheimer's but also in Parkinson's disease [99]; it causes the accumulation of soluble and toxic $A \beta$-aggregates and oxidative stress, and it is linked to the initiation of the tau cascade. In addition, signaling from the nucleus to mitochondria may be crucial for the regulation of mitochondrial function and aging, possibly contributing to the development of age-associated diseases such as AD. Mitochondria not only play a central role in metabolic pathways, they also regulate cell fate through crosstalk between autophagy and apoptosis. Macroautophagy (autophagy) and apoptosis are intimately interconnected and determine whether cells survive or die [100].

On the other hand, genes define a baseline mitochondrial function, where maternal mtDNA contributes more, and environmental factors determine the rate of mitochondrial function, with less durability producing faster brain aging. Mitochondrial function influences AD, APP 
expression and processing and $\mathrm{A} B$ accumulation [101, 102]. Also in familiar AD (FAD), the impaired mitochondrial function is caused by PS (either PS 1 or PS 2) mutations, but about $10 \%$ are inherited, most of the cases are sporadic AD (SAD). Both FAD and SAD share the features of accumulated extra and intracellular A $\beta$ plaques, as well as intracellular NFTs and cell atrophy and cell death, suggesting a common pathogenic origin on the basis of the intracellular $\mathrm{Ca}^{2+}$-homeostasis disruption tested in a mutant PS with a mitochondrial dysfunction with potential cell death [103]. Xie et al. used APP/PS1 transgenic mice to study the temporal relationship among $\mathrm{A} \beta$ plaque deposition, oxidative stress, and cell death, identified $\mathrm{A} \beta$ as the mediator of oxidative stress and subsequent neurodegeneration. Oxidative stress began in neurites and was followed by the appearance of $A \beta$ plaques in the surrounding tissue ultimately leading to oxidation in neuronal soma, but the oxidized neurites survived for several weeks. The oxidation in neuronal soma was associated with caspase-dependent apoptosis [104]. In addition, intermediate cellular players, including astrocytes or microglia, responded to amyloid deposits with chemokine or cytokine signaling which, in turn, led to oxidation in neurites.

The Glutamate (Glu) and mitochondria have a relationship in oxidative stress that underlies $\mathrm{AD}$; Glu is an important neurotransmitter in neurons and glial cells, and is strongly dependent on calcium homeostasis and mitochondrial function [105]. Mitochondrial deficits occur early in $\mathrm{AD}$, even before plaque formation [106]. Decreased expression of cytochrome c oxidase $(\mathrm{COX})$ and pyruvate dehydrogenase $(\mathrm{PDH})$ has also been detected in postmortem brain tissue of patients with $\mathrm{AD}$, as well as in animal models. Substances used to maintain brain metabolism in the 3xTg-AD mouse model, such as icariin active component of the traditional Chinese herbal medicine Epimedium, could modulate neuronal cell activity, preserve mitochondria and functional synaptic proteins, inhibit Abfix expression and improve cognitive functions in AD mice [107].

\subsection{Nutrition and AD}

Genetic and environmental factors are particularly important for the sporadic form of AD. Diets rich in saturated fatty acids and alcohol but deficient in antioxidants and vitamins appear to promote the onset of the disease. In contrast, diets rich in antioxidants, vitamins B6, B12 and folate, unsaturated fatty acids, and fish suppress its onset [108]. During the last decade, many investigations have shown metabolic disturbances (obesity and metabolic syndrome) to be risk factors for the development of dementias and even AD [109]. Obesity is related to vascular diseases, and there is increasing evidence linking vascular risk factors to dementia and AD [109]. Instead of exploring the effect of its subcomponents, several studies have assessed the relationship between metabolic syndrome as a whole and the risk of $\mathrm{AD}$ or cognitive decline [111-113]. The cellular mechanisms involved in the AD associated with metabolic alterations are now becoming more understandable. It is well known that an optimal supply of nutrients is necessary to maintain normal functioning of the brain. Thus, the impact of poor nutrition (overweight, obesity) on the development of AD and the importance of good nutrition as a preventive strategy to reduce the incidence of dementias and AD are clear. 
Malnutrition is associated with increased morbidity and mortality in patients with AD, with sleep disturbances, psychological problems, immobility, falls and increased hospitalization risk [114]. Normal human aging is also associated with vitamin deficiencies. One study in an Alzheimer transgenic mouse (VCT2+/-APP/PSEN1) found decreased ascorbic acid and increased oxidative stress in the brain as well as for Alzheimer's disease [115].

Antioxidant nutrients may help to protect these affected brain regions. Plasma vitamin C levels are lower in subjects with dementia compared to controls, supporting the free radical theory of oxidative neuronal damage [116]. Despite years of scientific, medical and clinical advances in this area, much work remains to discover specific nutritional interventions for the prevention of AD. Promising agents such as vitamins, energy substrates, flavonoids, lipids and modified diets functioning as antioxidants, metabolic enhancers, immune modulators and direct disease-modifying agents await further investigation [117].

\subsection{Malnutrition and senescence hypothesis of $\mathrm{AD}$ progression}

It is well known that adequate nutrition is an important factor in order to maintain cognitive function, particularly during aging. Malnutrition is among the risk factors for developing mild cognitive impairment and AD in which a cognitive decline is correlated with synaptic loss. The synapses are part of the neuronal membrane and are continuously being remodeled; therefore, ensuring the availability of sufficient levels of nutritional precursors (i.e., uridine monophosphate, choline and omega-3 fatty acids) to make the phospholipids required to build neuronal membranes may reduce synaptic degeneration in AD. Also, B-vitamins, phospholipids and other micronutrients act as cofactors to enhance the supply of precursors required to make neuronal membranes and synapses. Vitamin D has a role in brain physiology as well, for instance, by promoting neurotransmission, neurogenesis, synaptogenesis, amyloid clearance and preventing neuronal death [118].

Undernutrition during early life results in deficits in the spatial learning capacity of the animals [118], as shown by a wide variety of behavioral tests, and it is known to cause changes in the developing brain that affect the morphology, particularly in the granule cells of the dentate gyrus [120-122]. Prenatal malnutrition and chronic malnutrition in the aged rats cause abnormal mitochondrial, swollen Golgi membrane system, increase in multivesicular bodies and lypofuscine density in neurons of the hippocampus [123]. Since the mitochondrion is responsible for the production of ATP, its dysfunction induces a senescence response [124]. Furthermore, mitochondrial autophagocytosis is believed to be a major contributor to lipofuscin formation [125]. Autophagocytosis of mitochondria is also prominent in AD, because the accumulated autophagic vacuoles in dystrophic neurites contribute to the local production of $A \beta$ within plaques, and the generalized increase in autophagy in the neuropil could be a significant source of $\mathrm{A} \beta$ overproduction in the $\mathrm{AD}$ brain. Thus, a link between mitochondrial dysfunction/oxidative stress and autophagy has been reported to occur in AD [126]. In addition, lipofuscin can be used as a biomarker to detect senescence [127], since it is one of the "age pigments", autofluorescent cell products from lysosomes that diverge in number and size among brain regions. 
The increase in lipid components is possibly due to modifications in neuronal metabolism with age [128]. In Ref. [129], Giacone et al. proposed the "lipofuscin hypothesis of AD", in which the first step in the genesis of senile plaques is the release of lipofuscin free into the neuropil, where it cannot be rapidly degraded due to its biochemical characteristics. Therefore, the lipofuscin may persist in the extracellular milieu, giving rise to a focal impairment that can initiate the senile plaque and serving as a source of $A \beta$ oligomers for a prolonged period of time. This idea is supported by the hydrophobic and insoluble characteristics of lipofuscin, which mimic those of substances that are the most effective in inducing an innate immune response [130]; the rate of lipofuscin formation is also closely related to oxidative stress [131].

\subsection{Senescence hypothesis and microglial aging}

Cellular senescence is a terminal phase of mitotic cells characterized by permanent cell-cycle arrest; it can be induced by a variety of stressors, including reactive oxygen species. One hypothesis is that senescent cells contribute to aging by altering cells and its secretory phenotype, as well as to the development of age-associated diseases such as AD [132].

It has been suggested that neuroinflammation, mediated by the brain's innate immune system, contributes to AD neuropathology and exacerbates the course of the disease. Some studies found that a systemic immune challenge during late gestation predisposes mice to develop AD-like neuropathology during aging when there are elevated levels of inflammatory cytokines and hippocampal amyloid precursor protein (APP), altered tau phosphorylation and missorting to somatodendritic compartments. All these effects produced significant impairments in working memory in old age [34]. Also, AD and brain aging share common molecular changes, and $\mathrm{AD}$ could be a form of accelerated brain aging. In addition, in AD senescent mechanisms are present in all cells, including glia and neurons. Evidence indicates that vascular impairment is a fundamental contributor to $\mathrm{AD}$ pathology, and platelets are generally considered a key element because they represent the link between $\mathrm{A} \beta$ deposition, peripheral inflammation and endothelial senescence. AD is superimposed onto the normal process of aging and one important facet of aging is the accumulation of senescent cells that lose the ability to proliferate, and also release cytokines and proteases, collectively known as the senescence-associated secretory phenotype, which contribute to the chronic inflammatory environment seen in the old age [133]. In brain, astrocytes clearly play a role in modulating neuronal function and survival in health but in disease are senescent [134]. Also, human astrocyte lines expressing the toxic form of $A \beta$ rapidly reached a senescent state in vitro [135].

In the other hand, observations suggest that chronic systemic inflammation induces in middleaged rats intense neuroinflammation evoked by senescent-type microglia and may contribute to the initiation and progression of $\mathrm{AD}$, resulting in cognitive impairment. Also, with chronic inflammatory bone disorders, pro-inflammatory blood cells and bacterial components including lipopolysaccharides (LPS), activate the receptors localized on the surface of leptomeningeal cells, which in turn activate brain-resident microglia to evoke neuroinflammation [136]. Furthermore, the maternal immune response predisposes the offspring to develop neuropsychiatric disorders and can prime microglia cells to produce high levels of cytokines with a second stimulus [137]. Prenatal immune activation of offspring changes the 
integrity of the gastrointestinal barrier [138], which probably increases exposure to antigens with pathogen-associated molecular patterns, such as LPS. Exposure to Poly (I:C) on the late gestational day can alter cognitive performance in the adult or aged animals [34, 139]. Highfat diets can also cause metabolic endotoxemia (an increased LPS concentration in plasma from microbiota in the gut) with a pro-inflammatory response [140]. This gut microbiota LPS accelerates aging, with an increase in the concentration of pro-inflammatory cytokines and of protein 16 (p16), which is a senescence biomarker in the colon [141]. The senescent cells produce chemokines, cytokines, growth and differentiation factors and matrix-remodeling enzymes, collectively known as the senescence-associated secretory phenotype [142, 143], which can contribute to tissue dysfunction [142] as Alzheimer's diseases [144]. The possible mechanism is that chronic systemic inflammatory challenges induce differential age-dependent microglial responses. Microglia are the resident immune cells in the brain, providing its first line of defense and initiating the release of pro-inflammatory mediators to trigger neuroinflammation in response to autoimmune injury, infection, ischemia, toxic insults and trauma. They recognize a broad spectrum of molecular targets, such as glycolipids, lipoproteins, nucleotides, abnormally processed peptides, modified or aggregated proteins (i.e., A $\beta$ ), inflammatory cytokines, and damaged neurons, which are the strongest inducers of microglia activation [145]. In Ref. [99], Wu et al. propose a strong relationship between nutrients, microglia, aging and brain based on the concept of "microglia ageing." This concept considers microglia as the key contributor to the acceleration of cognitive decline, which is the major sign of brain aging. Senescent microglia display morphological changes: fewer and shorter processes, increased soma volume, and formation of spheroid swellings, collectively referred to as "dystrophic microglia." Furthermore, inflammation induces oxidative stress and DNA damage, leading to the overproduction of reactive oxygen species, including macrophages and microglia and promoting aging. Therefore, providing early treatment of inflammatory disorders and controlling microglia aging, may delay the onset and limit the severity and/or progression of $\mathrm{AD}[136]$.

Animal models are used to test changes in microglia. For example, in adult APP/PS1 mice, exercise enhances memory test performance and is associated with increased numbers of cholinergic and serotoninergic neurons, and reduced A $\beta$ levels and microglia activation [146]. Dietary restriction also appears to attenuate age-related activation of microglia, resulting in beneficial effects on neurodegeneration and cognitive decline [147]. Dietary restriction suppresses LPS-induced secretion of inflammatory cytokines, and shifts hypothalamic signaling pathways to an anti-inflammatory bias [148].

\section{6. $\beta$-Amyloidopathy and neuroinflammation in the pathogenesis of age-related AD}

The study of the aging organism allowed selection of a group of neurodegenerative diseases which have a similar mechanism of pathogenesis, including the pathological processes of protein aggregation and deposition in nerve tissue. The AD pathogenesis in $\beta$-amyloidopathy is a manifestation of proteinopathy leading to cytotoxicity, neurodegeneration and the development of pathological apoptosis activated by the formation of intracellular $A \beta[166]$. 
Proteinopathy-induced cell senescence is caused by the accumulation of misfolded proteins and activation of the innate immune system, with the production of pro-inflammatory cytokines, chemokines and oxidative stress that trigger chronic inflammation and ultimately, senescence. Components of SASP and proteinopathy can induces more senescent cells. These cells are resistant to apoptosis, but can die by autophagy. Senescent cells can be the link between $A ß$ and secondary proteinopathies such as tau, $\alpha$-synuclein and TDP-43 [149]. Indirect evidence that infection could be a cause of $\mathrm{AD}$ has been reported, and it was suggested that invasion by a virus could cause activation of microglia and pericytes and ultimately, amyloid deposition [150].

Systemic infections and persistent neuroinflammation are risk factors for developing AD [151]. Mice injected on gestational day 17 with poly I:C (a mimic of virus exposure) show, at 15 months, an increase in APP and its proteolytic fragments, hyperphosphorylation of tau without NFTs and the absence of significant $A \beta$ accumulation, but these parameters have not yet been determined in aged mice [34]. Indirect evidence that infection could be a cause of AD has been reported by Wisniewski et al., who suggested that invasion by a virus could cause activation of microglia and pericytes and ultimately, amyloid deposition [152].

The infectious hypothesis is suggested by the altered blood-brain barrier and the activation of neuroinflammation in the brain, which could decrease $A ß$ peptide clearance. For example, infection by Helicobacter pylori is acquired during childhood and often persists for life, inducing a chronic gastric inflammation that remains asymptomatic but can induce systemic inflammation and increase homocysteine levels, contributing to the risk of AD. In animal models of $\mathrm{AD}(5 \mathrm{xFAD})$, in which glutamate excitotoxicity through NMDA receptors involves neuroinflammation, however, apart from $\mathrm{A} \beta$ reductions, improvements were no longer observed in the $5 x F A D$ model during advanced stages of the disease, which may reflect the limited efficacy of memantine in clinical settings [153].

\subsection{Amyloid cascade hypothesis}

The amyloid cascade hypothesis postulates that memory deficits are caused by increased brain levels of $\mathrm{A} \beta$ peptide, which are derived from the larger amyloid precursor protein (APP) by sequential proteolytic processing [154]. This hypothesis is a neuron-centric, linear and quantitative model postulating direct cause and consequences in a cascade initiated by Abfix deposition and leading progressively to Tau pathology, synaptic dysfunction, inflammation, neuronal loss and ultimately, to dementia. Earlier AD mouse models have generated a wealth of information that has significantly improved our knowledge about AD; however, the amyloid cascade hypothesis remains controversial, because the majority of these models are based on transgenic overexpression of APP in combinations with different familial ADassociated mutations in APP or PS 1. Overexpression of APP generates elevated A $\beta$ levels to mimic the $\mathrm{A} \beta$ amyloidosis of $\mathrm{AD}$ brains, but concomitant with this it produces non-physiological effects and a number of undesirable side effects. One strategy is to introduce mutations into the mouse APP gene and new models (APPNL-F and APP ${ }^{\mathrm{NLG}-\mathrm{F}}$ ) that develop robust $\mathrm{A} \beta$ amyloidosis, which induces synaptic degeneration and memory impairments [155]. 
The quantitative aspects of the hypothesis imply that reducing the number of $A \beta$-plaques or the concentration of $A \beta$-oligomers should be sufficient to halt progression of AD. Thus, a minor increase in the $A \beta_{42}: A \beta_{40}$ ratio stabilizes toxic oligomeric species with intermediate conformations. The toxic impact of these Abfix species on the synapse but can spread into cells, producing neuronal death; Kuperstein et al. [156], suggest that there is a dynamic equilibrium between toxic and non-toxic intermediates.

In addition, it is well known that diffusible $A \beta$ oligomers are the major toxic agents in $A D$, and both monomers and oligomers are important for the early diagnosis of dementia because they are potential predictors for the progression of $\mathrm{AD}$ and are useful to evaluate new drugs against $\operatorname{AD}[157,158]$.

A quarter to a third of older people has amyloid burdens without symptoms of dementia [159]. Various APP transgenic mice do not have all the characteristics of AD: they exhibit little or no neuron loss and not all of them develop cognitive impairments, even if for three-quarters of their lives they have deposits of amyloid, suggesting that $A \beta$ alone is not sufficient. Thus, they are a model of asymptomatic AD $[159,160]$.

\section{Animal models for AD study}

AD investigations have been conducted traditionally by studying human brains (autopsy) or by producing specific brain lesions in mice. The generation of animal models is particularly relevant, because they have been designed to test neurodegeneration with characteristics similar to those in the human brain, allowing us to design new therapeutic approaches. These models are key tools for in-depth studies of neurodegenerative diseases like AD.

Many studies of AD are based on experimental models in mice since their genome is nearly 99\% homologous with human [161]. Transgenic mouse models recapitulate the major hallmarks of AD and have been utilized since the early 1990s to explore in detail mechanisms underlying the disease pathology; they have provided excellent opportunities to analyze the bases for the temporal evolution of AD brains and to delineate the basic mechanisms that cause cellular dysfunction.

At present, there are many transgenic mouse and knockout models to analyze certain aspects of $\mathrm{AD}$ pathology, allowing the exploration of uncharted territories; they have revealed new pathogenic possibilities, many of which have not yet been demonstrated in humans. On the other hand, some discrepancies between the data obtained in the mice and in man remain unexplained [162]. Mice lack certain important aspects of AD; for example, age is an important factor in AD, but these animals have a short life, between 2 and 4 years. Also, the amyloid protein in mice, derived from proteolysis of the APP precursor, is different from that in human [163]. In spite of that, diverse studies in this mouse model showed the presence of soluble $\mathrm{A} \beta$ oligomers at prefibrillar stages that can act as toxic ligands at postsynaptic compartments, driving the synaptic in neuronal populations localized in similar areas to those affected in the human pathology with memory alterations. They have also been instrumental in validating dug targets in special cerebral areas to control memory. 
The triple transgenic (3xTg-AD) mouse, which develops pathologies associated with $\mathrm{AD}$, was created in 2003 (Figure 1). To produce this model, Oddo's team simultaneously microinjected two genes (APP and tau) into single-cell PS1M146V mouse embryos (transgenic mice that overexpress human or wild-type APP, and are hybrids from the 129/C57BL6 strain). These mice develop both amyloid plaques and NFT-like pathology in a progressive and agedependent manner associated with anatomical and temporal analogously to that observed in the human $\mathrm{AD}$ brain [16]. In this 3xTg-AD, $\mathrm{A} \beta$ deposits initiate in the cortex and progress to the hippocampus with aging (Figure 2). Amyloid accumulation is localized in the basal neocortex as well as in entorhinal areas, but this accumulation can also expand into the hippocampus. The conformational or hyperphosphorylation changes characteristic of tau pathology occur particularly in pyramidal neurons of the hippocampal CA1 subfield and in cortical structures (Figure 3) and evolve in the AD brain [164].

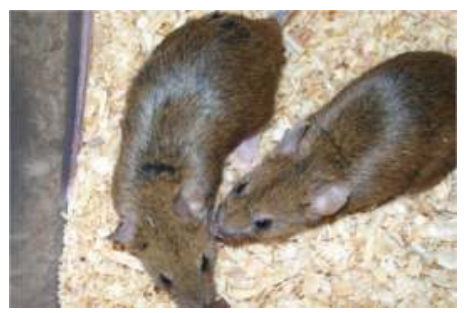

Figure 1. Triple transgenic mouse (3xTg-AD).
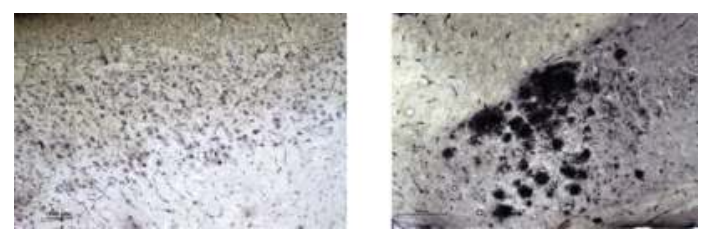

Figure 2. Photomicrographs of the amyloid beta in triple transgenic mouse in the cerebral cortex of 11-month-old female showing the staining for amyloid beta aggregates mice stained by immunohistochemistry using a BAM-10 antibody.
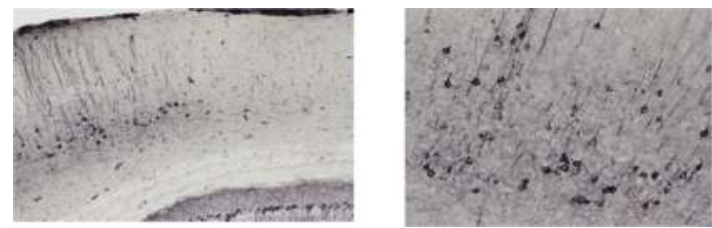

Figure 3. Photomicrographs of the cerebral cortex of an 11-month-old female mouse stained by immunohistochemistry using 499 tau antibody, showing the presence of human tau protein in two magnifications. 
Anothercharacteristic of the 3xTg-ADmouseis that thebrain regions severely affected, including the hippocampus, entorhinal cortex, amygdala, neocortex, and some subcortical areas such as basal forebrain where the acetylcholine (Ach) neurotransmitter is altered in the brains of individuals with mild AD due to low choline acetyltransferase (ChAT) activity [165-167].

The 3xTg-AD mouse has fewer ChAT-immunopositive neurons in the Meynert nucleus (primary source of cholinergic neurons), as well as a reduced density of ChAT-positive cholinergic fibers projecting to the primary motor cortex and the CA1 area of the hippocampus [168]. These cognitive dysfunctions are caused by massive loss of cholinergic neurons in the anterior basal brain, the area most vulnerable to the development of the pathological characteristics associated with AD. Alterations in cholinergic neurotransmission in the patients' neocortex and hippocampus are associated with the early stages of memory loss [168]. We also found a $50 \%$ reduction in nest-building quality (a task controlled by the hippocampus), associated with a significant increase in damaged neurons in the CA1 hippocampal area (26\%) compared to wild-type mice [170]. The decreased ability to carry out activities of daily living (humans) or to perform nest building correctly (3xTg-AD mice) are behavioral symptoms that can be studied and related to anatomical and morphological signs in the complex Alzheimer's disease syndrome.

\subsection{Sporadic models for Alzheimer's study}

A variety of animals can serve as experimental models of $\mathrm{AD}$, which are valuable tools for the design of new therapeutic strategies and to explore some other aspects of the disease, as some specimens develop amyloid plaques in their brain and cognitive dysfunctions similar to those of AD. Like humans, dogs develop amyloid plaques in their brains with advancing age, and some specimens suffer sporadic cases of Alzheimer's disease, age-related cognitive impairment with loss of short-term memory or working memory, changes in behavior, irritability, incontinence, and orientation problems [171]. Sarasa cloned and sequenced the canine APP, finding it virtually identical to human APP, including the peptide sequence corresponding to $\beta$-amyloid peptide. They analyzed the presence and distribution of amyloid plaques in the brains of healthy young and old dogs with severe cognitive dysfunction. With specific antibodies against AB40 and AB42, they found that the old demented animals had many amyloid and more mature plaques than older control dogs [163].

A nontransgenic rodent Octodon degus, which develops hallmarks of AD, could be a natural model to understand how sporadic $\mathrm{AD}$, between 12 and 36 months of age, develop the accumulation of $\mathrm{A} \beta$ oligomers and phosphorylated tau proteins. Moreover, agerelated changes in $A \beta$ oligomers and tau phosphorylation levels are correlated with decreases in spatial and object recognition memory, postsynaptic function, and synaptic plasticity [172].

Sparks and Schreurs proposed studying AD in rabbits fed a diet rich in cholesterol and copper. These animals develop amyloid plaques in their brains and deficiencies in learning complex tasks. They exhibit increased immunoreactivity to amyloid $\beta$ in neurons, the presence of extracellular plaques in the meninges, microgliosis, apoptosis, vascular activation of SOD, 
rupture of the blood-brain barrier and elevated brain levels of cholesterol; these data provide strong support for the suggestion that copper is implicated in the accumulation of Abfix [173].

Alzheimer's disease is of special interest to neuroscientists, not only because it is the most common of the brain degenerations but also because it is a multifactorial disorder of unknown etiology. In addition, recent evidence supports the hypothesis that persistent chronic infections produce increased $\mathrm{A} \beta$ (amyloidosis) in brain, and may be mediated by a response of the innate immune system. This hypothesis may give an explanation of the common pathogenic mechanisms and inflammatory gene polymorphisms involved in both AD and type 2 diabetes. In both diseases amyloidosis, that is, the accumulation of insoluble aggregates of fibrillar proteins, occurs in various organs and is often associated with bacterial infections [174]. Thus, the accumulation of intraneuronal amyloid- $\beta$ peptide $(A \beta)$ appears to be an early event in $A D$, suggesting its important role in the neurodegenerative process of $\mathrm{AD}$, because $\mathrm{A} \beta$ aggregates, particularly oligomers, may lead to synaptic dysfunction and neuronal loss, which are associated with memory and neural plasticity loss. Transgenic animal models are established to study the pathological role of intracellular $A \beta$ and to screen for drugs against $A \beta$ aggregation and associated toxicity, and they suggest that soluble, nonfibrillar $A \beta$ oligomers may induce synaptic failure early in AD. Despite their undoubted value, the transgenic models rely on genetic manipulations that represent the inherited and familial but not the most abundant, sporadic form of AD [175].

\section{Conclusions}

This review poses a historical overview of the pathology of Alzheimer's disease and provides an up to date of its features. Then, a molecular and histological follow-up of the proteins most strongly associated with this pathology is delivered. Finally, the diverse molecular and cellular current hypotheses seeking to disentangle the mechanisms of Alzheimer's disease and supported by research in animal models are analyzed. These models have been extremely useful in elucidating the mechanisms of Alzheimer's disease, including the numerous factors and conditions that contribute to the pathogenesis, which may have important implications providing new insight for current and future strategies to treat Alzheimer's disease and to reduce or delay its onset by preventing infection, inflammation and amyloidosis.

\section{Acknowledgements}

The authors would like to thank Azucena Aguilar for technical assistance, genotyping and colony management; special thanks to INB Units (Proteogenomics, Vivarium, Microscopy and Behavior). They also thank Dr. Dorothy Pless for proofreading of this manuscript. This work was supported in part by CONACYT: CB2012/178841, CB-2015-01/255399 and DGAPAUNAM IN203616 and IN203616 to SDC. 


\section{Author details}

Erika Orta-Salazar ${ }^{1}$, Isaac Vargas-Rodríguez ${ }^{1}$, Susana A Castro-Chavira ${ }^{1}$, Alfredo I. Feria-Velasco ${ }^{2}$ and Sofía Díaz-Cintra ${ }^{*}$

*Address all correspondence to: yodi@unam.mx

1 Institute of Neurobiology (INB), Developmental Neurobiology and Neurophysiology UNAM-JuriquillaQuerétaro, México

2 Laboratory of Cellular Neurobiology, Department of Cellular and Molecular Biology, CUCBA, University of Guadalajara Zapopan Jalisco, México

\section{References}

[1] Wolkow CA, Zou SM, Mattson P. Aging of the Nervous System, In: Wolf N S, editor. The Comparative Biology of Aging, Springer, 2010: p. 319-352. DOI:10.1007/978-90-4813465-6.

[2] Goedert M, Spillantini MG. A century of Alzheimer's disease, Science. 2006;314:777781. DOI:10.1126/science.1132814.

[3] Mayeux R, Stern Y. Epidemiology of Alzheimer disease. Cold Spring Harb Perspect Med. 2012;2(8). DOI: 10.1101/cshperspect.a006239.

[4] Suzman J, Beard RE. 2011. Global Health and Aging. National Institute on Aging, National Institutes of Health, U.S. Department of Health and Human Services, and World Health Organization.

[5] World Health Organization, Dementia: a public health priority, Dementia. 2012; 112. DOI:978 9241564458.

[6] Dzamba D, Harantova L, Butenko O, Anderova M. Glial cells - the key elements of Alzheimer's disease, Curr Alzheimer Res. 2016; 13 (8): 894-911. [Epub ahead of print]

[7] Choonara YE. Pillay V, du Toit L C, Modi G, Naidoo D, Ndesendo VM, Sibambo SR. Trends in the molecular pathogenesis and clinical therapeutics of common neurodegenerative disorders. Int J Mol Sci. 2009; 2510-2557. DOI:10.3390/ijms10062510.

[8] Amtul Z. Why therapies for Alzheimer's disease do not work: do we have consensus over the path to follow? Ageing Res Rev. 2016; 25: 70-84.

[9] Zetterberg H, Mattsson N. Understanding the cause of sporadic Alzheimer's disease Exp Rev Neurother. 2014;14: 621-630. 
[10] De Strooper B, Karran E. Review. The cellular phase of Alzheimer's disease, Cell. 2016;164:603-615. DOI:10.1016/j.cell.2015.12.056.

[11] Quon D, Wang Y, Catalano R, Scardina JM, Murakami K. Formation of beta-amyloid protein deposits in brains of transgenic mice, Nature. 1991;352:239-241.

[12] Xu ZQ, Huang H, Chen YL, Gao YY, Xu J, Marshall C, Cai ZY. Different expression patterns of amyloid- $\beta$ protein precursor secretases in human and mouse hippocampal neurons: a potential contribution to species differences in neuronal susceptibility to amyloid- $\beta$ pathogenesis. J Alzheimers Dis. 2016;51:179-195. DOI:10.3233/JAD-150634.

[13] Games D, Adams D, Alessandrini R, Barbour R, Borthelette P, Blackwell C, Carr T, Clemens J, Donaldson T, Gillespie F et al. Alzheimer-type neuropathology in transgenic mice overexpressing V717F $\beta$-amyloid precursor protein. Nature. 1995;373(6514):523537.

[14] Zhao L, Liu S, Wang Y, Zhang Q, Zhao W, Wang Z. Effects of curculigoside on memory impairment and bone loss via anti-oxidative character in APP / PS1 mutated transgenic Mice. PLoS One. 2015;10(7): e0133289. DOI:10.1371/journal.pone.0133289.

[15] Borchelt R C, Thinakaran G, Eckman CB, Lee MK, Davenport F, Ratovitsky T, et al., Familial Alzheimer's disease-linked presenilin 1 variants elevate A 1 - 42 / 1 - 40 ratio in vitro and in vivo. Neuron 1996;17: 1005-1013.

[16] Oddo S, Caccamo A, Shepherd JD, Murphy MP, Golde TE, Kayed R, et al., Tripletransgenic model of Alzheimer's disease with plaques and tangles: intracellular A and synaptic dysfunction. Neuron 2003;39: 409-421.

[17] Oddo S. Amyloid deposition precedes tangle formation in a triple transgenic model of Alzheimer's disease, Neurobiol Aging. 2003;24:1063-1070. DOI:10.1016/j.neurobiolaging.2003.08.012.

[18] Alzforum, http://www.alzforum.org/research-models. 2014.

[19] Lucke-Wold BP, Turner RC, Logsdon AF, Simpkins JW, Alkon DL, Smith KE, Chen YW, Tan Z, Huber JD, Rosen CL. Common mechanisms of Alzheimer's disease and ischemic stroke: the role of protein kinase $\mathrm{C}$ in the progression of age-related neurodegeneration. J Alzheimers Dis. 2015;43(3):711-724. DOI: 10.3233/JAD-141422.

[20] Graeber MP, Kösel S, Grasbon-Frodl E, Möller HJ. Histopathology and APOE genotype of the first Alzheimer disease patient, Auguste D. Neurogenética. 1998;1:223-228.

[21] Whitehouse PJ, Price DL, Clark AW, Coyle JT. Alzheimer disease: evidence for selective loss of cholinergic neurons in the nucleus basalis. Ann Neurol. 1981;10:122-126.

[22] Mufson, S.E. Counts, S.E. Perez, S.D. Ginsberg, Cholinergic system during the progression of Alzheimer's disease: therapeutic implications, Exp Rev Neurother. 2008; 8:1703-1718. DOI:10.1586/14737175.8.11.1703. 
[23] Selkoe DG. Alzheimer's disease: genes, proteins, and therapy. Physiol Rev. 2001;81:741766.

[24] Price JC, Morris JC. Tangles and plaques in nondemented aging and "preclinical" Alzheimer's Disease. Ann Neurol. 1999;45: 358-368. DOI:10.1002/1531-8249(199903)45.

[25] Mattson MP. Pathways towards and away from Alzheimer's disease. Nature. 2004;430: 631-639. DOI:10.1038/nature02621.

[26] Erten-Lyons D, Dodge HH, Woltjer R, Silbert LC, Howieson DB; Kramer P, Kaye JA., Neuropathological basis of age-associated brain atrophy, JAMA Neurol. 2013;70:616622. DOI:10.1001/jamaneurol.2013.1957.

[27] Delatour M, Guégan M, Volk A, Dhenain M. In vivo MRI and histological evaluation of brain atrophy in APP/PS1 transgenic mice. Neurobiol Aging. 2006;27:835-847.

[28] Gonzalez-Lima F, Berndt JD, Valla JE, Games D, Reiman EM. Reduced corpus callosum, fornix and hippocampus in PDAPP transgenic mouse model of Alzheimer's disease. Neuroreport. 2001;12(11):2375-2379.

[29] Redwine JM, Kosofsky B, Jacobs RE, Games D, Reilly JF, Morrison JH, Young WG, Bloom FE. Dentate gyrus volume is reduced before onset of plaque formation in PDAPP mice: a magnetic resonance microscopy and stereologic analysis. Proc Natl Acad Sci USA. 2002;100(3): 1381-1386.

[30] Valla J, Schneider LE, Gonzalez-Lima M, Reiman EM. Nonprogressive transgenerelated callosal and hippocampal changes in PDAPP mice. Neuroreport. 2006;17:2932.

[31] Yin J, Turner GH, Coons SW, Maalouf M, Reiman EM, Association of amyloid burden, brain atrophy and memory deficits in aged apolipoprotein $\varepsilon 4$ mice. Curr Alzheimer Res. 2014;11:283-290. DOI:PMID: 24694076.

[32] Norden DM, Muccigrosso MM, Godbout JP. Neuropharmacology microglial priming and enhanced reactivity to secondary insult in aging, and traumatic CNS injury, and neurodegenerative disease. Neuropharmacology. 2015;96:29-41. DOI:10.1016/j.neuropharm.2014.10.028.

[33] Witcher KG, Eiferman DS, Godbout JP. Priming the inflammatory pump of the CNS after traumatic brain injury. Trends Neurosci. 2015;38:609-620. DOI:10.1016/j.tins. 2015.08.002.

[34] Krstic D, Madhusudan A, Doehner J, Vogel P, Notter T, Imhof C, Manalastas A, Hilfiker M, Pfister S, Schwerdel C, Riether C, Meyer U, Knuesel I. Systemic immune challenges trigger and drive Alzheimer-like neuropathology in mice. J Neuroinflammation. 2012;9:1-23. DOI: 10.1186/1742-2094-9-151.

[35] Mhatre SD, Tsai CA, Rubin AJ, James ML, Andreasson KI. Microglial malfunction: the third rail in the development of Alzheimer's disease. Trends Neurosci. 2015;38:621-636. 
[36] Lazarov O, Robinson J, Tang YP, Hairston IS, Korade-Mirnics Z, Lee VM, Hersh LB, Sapolsky RM, Mirnics K, Sisodia SS. Environmental enrichment reduces Abeta levels and amyloid deposition in transgenic mice. Cell 2005;120:701-713. DOI:10.1016/j.cell. 2005.01.015.

[37] Gonatas NK. Axonic and synaptic lesions in neuropsychiatric disorders. Nature. 1967;214(5086):352-5. PubMed PMID: 6032829.

[38] Masliah E, Terry R. The role of synaptic proteins in the pathogenesis of disorders of the central nervous system. Brain Pathol. 1993;3(1):77-85. Review. DOI:PMID: 8269086.

[39] Masliah E, Terry RD, DeTeresa RM, Hansen LA. Immunohistochemical quantification of the synapse-related protein synaptophysin in Alzheimer disease. Neurosci Lett. 1989;103(2):234-239.

[40] Scheff SW, Price DA. Synapse loss in the temporal lobe in Alzheimer's disease. Ann Neurol. 1993;33(2):109-199.

[41] Scheff SW, Price DA. Sparks DL. Quantitative assessment of possible age-related change in synaptic numbers in the human frontal cortex. Neurobiol Aging. 2001;22:355365. DOI:10.1016/S0197-4580(01)00222-6.

[42] Walsh DM, Selkoe DJ. Deciphering the molecular basis of memory failure in Alzheimer's disease. Neuron 2004;44: 181-193.

[43] Walsh DM, Selkoe DJ. Oligomers? A decade of discovery. J. Neurochem. 2007;101:11721184. DOI:10.1111/j.1471-4159.2006.04426.x.

[44] Morin JP, Cerón-Solano G, Velázquez-Campos G, Pacheco-López G, Bermúdez-Rattoni F. Spatial memory impairment is associated with intraneural amyloid- $\beta$ immunoreactivity and dysfunctional Arc expression in the hippocampal-CA3 region of a transgenic mouse model of Alzheimer's disease. J Alzheimer Dis. 2016;51: 69-79. DOI:PMID: 26836189.

[45] Wu J, Petralia RS, Kurushima H, Patel H, Jung MY, Volk L, Chowdhury S, Shepherd JD, Dehoff M, Li Y, Kuhl D, Huganir RL, Price DL, Scannevin R, Troncoso JC, Wong PC, Worley PF. Arc/Arg3.1 regulates an endosomal pathway essential for activitydependent $\beta$-amyloid generation. Cell. 2011;147:615-628. DOI:10.1016/j.cell. 2011.09.036.

[46] Kerrigan, A.D. Randall, H.L. A new player in the "synaptopathy" of Alzheimer's disease- Arc/Arg 3.1. Front Neurol 2013;4:1-7. DOI:10.3389/fneur.2013.00009.

[47] Marin R, Rojo JA, Fabelo N, Fernandez CE, Diaz M. Lipid raft disarrangement as a result of neuropathological progresses: a novel strategy for early diagnosis? Neuroscience. 2013;245:26-39. DOI:10.1016/j.neuroscience.2013.04.025.

[48] Delint-Ramirez I, Fernández E, Bayés A, Kicsi E, Komiyama NH, Grant SG. In vivo composition of NMDA receptor signaling complexes differs between membrane 
subdomains and is modulated by PSD-95 and PSD-93. J Neurosci. 2010;30:8162-8170. DOI:10.1523/JNEUROSCI.1792-10.2010.

[49] Braak H, Braak E. Evolution of neuronal changes in the course of Alzheimer's disease. J Neural Transm Suppl. 1998;53:127-40. Review. PubMed PMID: 9700651.

[50] Roberts GW, Gentleman SM, Lynch A, Murray L, Landon M, Graham DI. Beta amyloid protein deposition in the brain after severe head injury: implications for the pathogenesis of Alzheimer's disease. J Neurol Neurosurg Psychiatry. 1994;57: 419-425.

[51] Recuero M, Serrano E, Bullido MJ, Valdivieso F. Abeta production as consequence of cellular death of a human neuroblastoma overexpressing APP. FEBS Lett. 2004;570:114118. DOI:10.1016/j.febslet.2004.06.025.

[52] Schmitt, HP. epsilon-Glycation, APP and Abeta in ageing and Alzheimer disease: a hypothesis. Med Hypotheses. 2006;66:898-906. DOI:10.1016/j.mehy.2005.11.016.

[53] Rosenkranz SC, Geissen M, Härter K, Szalay B, Ferrer I, Vogel J, Smith S, Glatzel M. Amyloid-precursor-protein-lowering small molecules for disease modifying therapy of Alzheimer's disease. PLoS One. 2013;18:8(12):e82255. DOI:10.1371/journal.pone. 0082255.

[54] Zahs KH. Ashe KH, "Too much good news" - are Alzheimer mouse models trying to tell us how to prevent, not cure, Alzheimer's disease? Trends Neurosci. 2010;33:381389. DOI:10.1016/j.tins.2010.05.004.

[55] Schenk D, Barbour R, Dunn W, Gordon G, Grajeda H, Guido T, Hu K, Huang J, JohnsonWood K, Khan K, Kholodenko D, Lee M, Liao Z, Lieberburg I, Motter R, Mutter L, Soriano F, Shopp G, Vasquez N, Vandevert C, Walker S, Wogulis M, Yednock T, Games $\mathrm{D}$, Seubert P. Immunization with amyloid- $\mathrm{b}$ attenuates Alzheimer- disease-like pathology in the PDAPP mouse. Nature. 1999;400:173-177.

[56] Awasthi M, Singh S, Pandey VP, Dwivedi UN. Alzheimer's disease: an overview of amyloid beta dependent pathogenesis and its therapeutic implications along with in silico approaches emphasizing the role of natural products. J Neurol Sci. 2016;361:256271. DOI:10.1016/j.jns.2016.01.008.

[57] Foley JA, Cocchini G, Logie RH, Della Sala S. No dual-task practice effect in Alzheimer's disease. Memory 2015;23(4): 518-528.

[58] Westerman MA, Cooper-Blacketer D, Mariash A, Kotilinek L, Kawarabayashi T, Younkin LH, Carlson GA, Younkin SG, Ashe KH. The relationship between Abeta and memory in the Tg2576 mouse model of Alzheimer's disease. J Neurosci. 2002;22(5): 1858-1867.

[59] Lok K, Zhao H, Zhang C, He N, Shen H, Wang Z, Zhao W, Yin M. Effects of accelerated senescence on learning and memory, locomotion and anxiety-like behavior in APP/PS1 mouse model of Alzheimer's disease. J Neurol Sci. 2013;335:145-154. DOI:10.1016/j.jns. 2013.09.018. 
[60] Sterniczuk R, Antle MC, Laferla FM, Dyck RH. Characterization of the 3xTg-AD mouse model of Alzheimer's disease: part 2. Behavioral and cognitive changes. Brain Res. 2010; 1348:149-55. DOI: 10.1016/j.brainres.2010.06.011.

[61] Haan J, Roos RA, Bakker E. No protective effect of apolipoprotein E epsilon 2 allele in Dutch hereditary cerebral amyloid angiopathy. Ann Neurol. 1995; 37(2):282. DOI: 10.1002/ana.410370223.

[62] Peila R, Rodriguez BL, Launer LJ; Honolulu-Asia Aging Study. Type 2 diabetes, APOE gene, and the risk for dementia and related pathologies: the Honolulu-Asia Aging Study. Diabetes. 2002;51(4):1256-1262

[63] Irie F, Fitzpatrick AL, Lopez OL, Kuller LH, Peila R, Newman AB, Launer LJ. Enhanced risk for Alzheimer disease in persons with type 2 diabetes and APOE epsilon4: the Cardiovascular Health Study Cognition Study. Arch Neurol. 2008;65(1):89-93. DOI: 10.1001/archneurol.2007.29.

[64] Matsuzaki T, Sasaki K, Tanizaki Y, Hata J, Fujimi K, Matsui Y, Sekita A, Suzuki SO, Kanba S, Kiyohara Y, Iwaki T. Insulin resistance is associated with the pathology of Alzheimer disease: the Hisayama study. Neurology. 2010;75:764-770. DOI: 10.1212/ WNL.0b013e3181eee25f.

[65] Siegel G, Mockenhaupt FH, Behnke AL, Ermilov E, Winkler K, PriesAR, Malmsten M, Hetzer R, Saunders R, Lindman B. Lipoprotein binding to anionic biopolyelectrolytes and the effect of glucose on nanoplaque formation in arteriosclerosis and Alzheimer's disease. Adv Colloid Interface Sci. DOI:10.1016/j.cis.2016.02.001.

[66] Harold D, Abraham R, Hollingworth P, Sims R, Gerrish A, Hamshere ML, Pahwa JS, Moskvina V, Dowzell K, Williams A, et al. Genome-wide association study identifies variants at CLU and PICALM associated with Alzheimer's disease. Nat Genet. 2010;41:1088-1093. DOI:10.1038/ng.440.Genome-wide.

[67] Lambert JC, Heath S, Even G, Campion D, Sleegers K, Hiltunen M, Combarros O, Zelenika D, Bullido MJ, Tavernier B, Letenneur L, et al. Genome-wide association study identifies variants at CLU and CR1 associated with Alzheimer's disease. Nat Genet. 2009;41(10):1094-1099. DOI:ng.439 [pii] \r10.1038/ng.439.

[68] Dowell NG, Evans SL, Tofts PS, King SL, Tabet N, Rusted JM. Jennifer. Structural and resting-state MRI detects regional brain differences in young and mid-age healthy APOE-e4 carriers compared with non-APOE-e4 carriers. 2016 NMR Biomed. 2016;29:118. DOI: $10.1002 / \mathrm{nbm} .3502$.

[69] Liu CC, Kanekiyo T, Xu H, Bu G. Apolipoprotein E and Alzheimer disease: risk, mechanisms and therapy. Nat Rev Neurol. 2013;9(2):106-18. DOI: 10.1038/nrneurol. 2012.263.

[70] Colton CA, Brown CM, Cook D, Needham LK, Xu Q, Czapiga M, Saunders AM, Schmechel DE, Rasheed K, Vitek MP. APOE and the regulation of microglial nitric 
oxide production: a link between genetic risk and oxidative stress. Neurobiol Aging. 2002;23:777-785. DOI:10.1016/S0197-4580(02)00016-7.

[71] Goedert M, Jakes R. Mutations causing neurodegenerative tauopathies. Biochim Biophys Acta. 2005;1739(2-3):240-250. Review DOI:10.1016/j.bbadis.2004.08.007.

[72] Gómez-Isla T, Hollister R, West H, Mui S, Growdon JH, Petersen RC, Parisi JE, Hyman BT. Neuronal loss correlates with but exceeds neurofibrillary tangles in Alzheimer's disease. Ann Neurol. 1997;41:17-24. PMID: 9005861.

[73] Kril JJ, Patel S, Harding AJ, Halliday GM. Neuron loss from the hippocampus of Alzheimer's disease exceeds extracellular neurofibrillary tangle formation. Acta Neuropathol. 2002; 103(4):370-376. DOI:10.1007/s00401-001-0477-5.

[74] Kondo J, Honda T, Mori H, Hamada Y, Miura R, Ogawara M, Ihara Y. The carboxyl third of tau is tightly bound to paired helical filaments. Neuron. 1988; 1(9):827-834. DOI:10.1016/0896-6273(88)90130-4.

[75] Braak H, Braak E. Neuropathological stageing of Alzheimer-related changes. Acta Neuropathol. 1991;82(4): 239-259.

[76] Braak H, Braak E. Frequency of stages of Alzheimer-related lesions in different age categories. Neurobiol Aging. 1997;18(4):351-357. PubMed PMID:9330961.

[77] Mena R, Edwards PC, Harrington CR, Mukaetova-Ladinska EB, Wischik CM. Staging the pathological assembly of truncated tau protein into paired helical filaments in Alzheimer's disease. Acta Neuropathol. 1996;91: 633-641. DOI:10.1007/s004010050477.

[78] Mena R and Luna-Muñoz J. Stages of pathological tau-protein processing in Alzheimer's disease: from soluble aggregations to polymerization into insoluble tau-PHFs, in: R.B. Maccioni, G. Perry (Eds.), Current Hypotheses and Research Milestones in Alzheimer's Disease. 2005: p. 247. DOI: 10.1007/978-0-387-87995-6.

[79] Terwel D, Lasrado R, Snauwaert J, Vandeweert E, Van Haesendonck C, Borghgraef P, Van Leuven F. Changed conformation of mutant Tau-P301L underlies the moribund tauopathy, absent in progressive, nonlethal axonopathy of Tau-4R/2N transgenic mice. J Biol Chem. 2005;280:3963-3973. DOI:10.1074/jbc.M409876200.

[80] Lewis J, Dickson DW, Lin WL, Chisholm L, Corral A, Jones G, Yen SH, Sahara N, Skipper L, Yager D, Eckman C, Hardy J, Hutton M, McGowan E. Enhanced neurofibrillary degeneration in transgenic mice expressing mutant tau and APP. Science. 2002;293(5534):1487-1491. DOI:10.1126/science.1062097.

[81] Higuchi M, Ishihara T, Zhang B, Hong M, Andreadis A, Trojanowski J, Lee VM. Transgenic mouse model of tauopathies with glial pathology and nervous system degeneration. Neuron. 2002;35:433-446.

[82] Lewis J, McGowan E, Rockwood J, Melrose H, Nacharaju P, Van Slegtenhorst M, Gwinn-Hardy K, Paul Murphy M, Baker M, Yu X, Duff K, Hardy J, Corral A, Lin WL, Yen SH, Dickson DW, Davies P, Hutton M. Neurofibrillary tangles, amyotrophy and 
progressive motor disturbance in mice expressing mutant (P301L) tau protein. Nat Genet. 2000;25(4):402-405. Erratum in: Nat Genet. 2000;26(1):127.

[83] Götz J, Chen F, van Dorpe J, Nitsch RM. Formation of neurofibrillary tangles in P3011 tau transgenic mice induced by Abeta 42 fibrils. Science. 2007;293(5534) 91-103. DOI: 10.1111/j.1750-3639.2007.00051.x.

[84] Lewis J, Dickson DW, Lin WL, Chisholm L, Corral A, Jones G, Yen SH, Sahara N, Skipper L, Yager D, Eckman C, Hardy J, Hutton M, McGowan E. Enhanced neurofibrillary degeneration in transgenic mice expressing mutant tau and APP. Science. 200;29;(5534):1487-1491.

[85] Pintana H, Apaijai N, Pratchayasakul W, Chattipakorn N, Chattipakorn SC. Effects of metformin on learning and memory behaviors and brain mitochondrial functions in high fat diet induced insulin resistant rats. Life Sci. 2012;91:409-414. DOI:10.1016/j.lfs. 2012.08.017.

[86] Barini E, Antico O, Zhao Y, Asta F, Tucci V, Catelani T, Marotta R, Xu H, Gasparini L. Metformin promotes tau aggregation and exacerbates abnormal behavior in a mouse model of tauopathy. Mol Neurodegener. 2016;11(1)16. DOI:10.1186/s13024-016-0082-7.

[87] Ontiveros-Torres MA, Labra-Barrios M L, Díaz-Cintra S, Vázquez-Aguilar A, MorenoCampuzano S, Flores-Rodríguez P, Luna-Herrera C, Mena R, Perry, G, Florán-Garduño B, Luna-Muñoz JL. Fibrillar amyloid- $\beta$ accumulation triggers an inflammatory mechanism leading to hyperphosphorylation of the carboxyl-terminal end of tau polypeptide in the hippocampal formation of the $3 \times \mathrm{Tg}-\mathrm{AD}$ transgenic mouse. J Alzheimer's Dis. DOI: 10.3233/JAD-150837.

[88] Cottrell EC, Ozanne SE. Early life programming of obesity and metabolic disease. Physiol Behav. 2007; 94: 17-28. DOI:10.1016/j.physbeh.2007.11.017.

[89] Miller DB, O'Callaghan JP. Do early-life insults contribute to the late-life development of Parkinson and Alzheimer diseases? Metabolism 2008;57:44-49. DOI:10.1016/ j.metabol.2008.07.011.

[90] Whalley LJ, Dick FD, McNeill G. A life-course approach to the aetiology of late-onset dementias. Lancet Neurol. 2006;5:87-96.

[91] Mittal K, Katare DP. Shared links between type 2 diabetes mellitus and Alzheimer's disease: a review. Diabetes Metab. Syndr. DOI:10.1016/j.dsx.2016.01.021.

[92] De La Monte SM, Metabolic derangements mediate cognitive impairment and Alzheimer's disease: role of peripheral insulin-resistance diseases. Panminerva Med. 2012;54(3):171-178.

[93] de la Monte SM. Type 3 Diabetes is sporadic Alzheimer's disease: mini-review. Eur Neuropsychopharmacol. 2014;24:1954-1960. DOI:10.1016/j.euroneuro.2014.06.008.

[94] Hoyer S, Nitsch R, Oesterreich K. Predominant abnormality in cerebral glucose utilization in late-onset dementia of the Alzheimer type: a cross-sectional comparison 
against advanced late-onset and incipient early-onset cases. J Neural Transm Park Dis Dement Sect. 1991;3:1-14.

[95] Steen E, Terry BM, Rivera EJ, Cannon JL, Neely TR, Tavares R, Xu XJ, Wands JR, de la Monte SM. Impaired insulin and insulin-like growth factor expression and signaling mechanisms in Alzheimer's disease - is this type 3 diabetes? J Alzheimers Dis. 2005; $7: 63-80$.

[96] Rivera EJ, Goldin A, Fulmer N, Tavares R, Wands JR, de la Monte SM. Insulin and insulin-like growth factor expression and function deteriorate with progression of Alzheimer's disease: link to brain reductions in acetylcholine, J Alzheimers Dis. 2005;8:247-68.

[97] Grieb P, Intracerebroventricular streptozotocin injections as a model of Alzheimer's disease: in search of a relevant mechanism. Mol. Neurobiol. 2016;53(3)1-12. DOI: 10.1007/s12035-015-9132-3

[98] Wu Z, Yu J, Zhu A, Nakanishi H. Nutrients, microglia aging, and brain aging. Oxid Med Cell Longev. 2016:7498528. DOI:10.1155/2016/7498528.

[99] Fang EF, Scheibye-Knudsen M, Chua KF, Mattson MP, Croteau DL, Bohr VA. Nuclear DNA damage signalling to mitochondria in ageing. Nat Rev Mol Cell Biol. 2016;17(5): 308-321. DOI:10.1038/nrm.2016.14.

[100] Grimm A, Friedland K, Eckert A. Mitochondrial dysfunction: the missing link between aging and sporadic Alzheimer's disease, Biogerontology. 2016;17(2):1-16.

[101] Swerdlow RH, Burns JM, Khan SM. The Alzheimer's disease mitochondrial cascade hypothesis: progress and perspectives. Biochim Biophys Acta - Mol. Basis Dis. 2014;1842:1219-1231. DOI:10.1016/j.bbadis.2013.09.010.

[102] Toglia P, Cheung KH, Mak DD, Ullah G. Impaired mitochondrial function due to familial Alzheimer's disease-causing presenilins mutants via $\mathrm{Ca}(2+)$ disruptions. Cell Calcium. DOI:10.1016/j.ceca.2016.02.013.

[103] Xie H, Hou S, Jiang J, Sekutowicz M, Kelly J, Bacskai BJ. Rapid cell death is preceded by amyloid plaque-mediated oxidative stress. Proc Natl Acad Sci USA. 2013;110(19): 7904-7909. DOI:10.1073/pnas.1217938110.

[104] Cassano T, Pace L, Bedse G, Lavecchia AM, De Marco F, Gaetani S, Serviddio G. Glutamate and Mitochondria: two prominent players in the oxidative stress-induced neurodegeneration. Curr Alzheimer Res. 2016;13:185-197.

[105] Du H, Guo L, Yan S, Sosunov AA, McKhann GM, Yan SS. Early deficits in synaptic mitochondria in an Alzheimer's disease mouse model. Proc Natl Acad Sci USA. 2010;107:18670-18675. DOI:10.1073/pnas.1006586107.

[106] Chen YJ, Zheng HY, Huang XX, Han SX, Zhang DS, Ni JZ, He XY. Neuroprotective effects of icariin on brain metabolism, mitochondrial functions, and cognition in triple- 
transgenic Alzheimer's disease mice. CNS Neurosci Ther. 2016;22(1): 63-73. DOI: 10.1111/cns.12473.

[107] Luchsinger JA, Noble JM, Scarmeas N. Diet and Alzheimer's disease. Curr Neurol Neurosci Rep. 2007;7(5):366-372.

[108] Emmerzaal TL, Kiliaan AJ, Gustafson DR. 2003-2013: a decade of body mass index, Alzheimer's disease, and dementia. J Alzheimers Dis. 2015;43:739-755. DOI: 10.3233/ JAD-141086.

[109] Kivipelto M, Ngandu T, Fratiglioni L, Viitanen M, Kåreholt I, Winblad B, Helkala EL, Tuomilehto J, Soininen H, Nissinen A. Obesity and vascular risk factors at midlife and the risk of dementia and Alzheimer disease. Arch Neurol. 2005; 62(10):1556-1560. PubMed PMID: 16216938.

[110] Yaffe K, Weston AL, Blackwell T, Krueger KA. The metabolic syndrome and development of cognitive impairment among older women. Arch Neurol. 2009;66:324-328. DOI: 10.1001/archneurol.2008.566.

[111] Raffaitin C, Gin H, Empana JP, Helmer C, Berr C, Tzourio C, Portet F, Dartigues JF, Alpérovitch A, Barberger-Gateau P., Metabolic syndrome and risk for incident Alzheimer's disease or vascular dementia: the Three-City Study. Diabetes Care. 2009;32(1):169-174. DOI: 10.2337/dc08-0272.

[112] Solfrizzi V(1), Scafato E, Capurso C, D’Introno A, Colacicco AM, Frisardi V, Vendemiale G, Baldereschi M, Crepaldi G, Di Carlo A, Galluzzo L, Gandin C, Inzitari D, Maggi S, Capurso A, Panza F. Metabolic syndrome and the risk of vascular dementia: the Italian Longitudinal Study on Ageing. J Neurol Neurosurg Psychiatry. 2010;8: 433-440. DOI: 10.1136/jnnp.2009.181743

[113] Yildiz D, Büyükkoyuncu Pekel N, Kiliç AK, Tolgay EN, Tufan F. Malnutrition is associated with dementia severity and geriatric syndromes in patients with Alzheimer disease. Turk J Med Sci. 2015;45(5):1078-1081. DOI:10.3906/sag-1406-76.

[114] Warner TA, Kang JQ, Kennard JA, Harrison FE. Low brain ascorbic acid increases susceptibility to seizures in mouse models of decreased brain ascorbic acid transport and Alzheimer's disease. Epilepsy Res. 2015;110:20-25. DOI: 10.1016/j.eplepsyres. 2014.11.017.

[115] Charlton KE, Rabinowitz TL, Geffen LN, Dhansay MA. Lowered plasma vitamin C, but not vitamin E, concentrations in dementia patients. J Nutr Health Aging. 2004;8(2): 99-107.

[116] Swaminathan A. Jicha GA. Nutrition and prevention of Alzheimer's dementia. Front Aging Neurosci. 2014;6: 1-13. DOI:10.3389/fnagi.2014.00282.

[117] Brouwer-Brolsma EM, de Groot LC. Vitamin D and cognition in older adults: an update of recent findings, Curr Opin Clin Nutr Metab Care. 2015;18:11-6. DOI: 10.1097/MCO. 0000000000000114. 
[118] Bedi KS. Spatial learning ability of rats undernourished during early postnatal life. Physiol. Behav. 1992;51: 1001-1007.

[119] Cintra L, Díaz-Cintra S, Galván A, Kemper T, Effects of protein undernutrition on the dentate gyrus in rats of three age groups. Brain Res. 1990;532:271-277. PMID: 2282520 .

[120] Levitsky DA, Strupp BJ. Malnutrition and the brain: changing concepts, changing concerns. J Nutr. 1995;125: 2212S-2220S.

[121] Almeida SS, Tonkiss J, Galler JR. Prenatal protein malnutrition affects avoidance but not escape behavior in the elevated T-maze test. Physiol Behav. 1996;60: 191-195. DOI: 10.1016/0031-9384(95)02209-0.

[122] Castro-Chavira AS, Aguilar-Vázquez AR, Martínez-Chávez Y, Palma L, Padilla-Gómez E, Diaz-Cintra S. Effects of chronic malnourishment and aging on the ultrastructure of pyramidal cells of the dorsal hippocampus. Nutr Neurosci. 2015;1-8. DOI: 10.1179/1476830515Y.0000000009.

[123] Wiley CD, Velarde MC, Lecot, Liu S, Sarnoski EA, Freund A, Shirakawa K, Lim HW, Davis SS, Ramanathan A, Gerencser AA, Verdin E, Campisi J. Mitochondrial dysfunction induces senescence with a distinct secretory phenotype. Cell Metab. 2015;23(2): 303-314. DOI: 10.1016/j.cmet.2015.11.011

[124] Gray DA, Woulfe J. Lipofuscin and aging: a matter of toxic waste. Sci Aging Knowl Environ. 2005;5: re1. DOI:10.1126/sageke.2005.5.re1.

[125] Moreira PI, Carvalho C, Zhu X, Smith MA, Perry G. Mitochondrial dysfunction is a trigger of Alzheimer's disease pathophysiology. Biochim Biophys Acta. 2010;1802: 210. DOI:10.1016/j.bbadis.2009.10.006.

[126] Georgakopoulou EA(1), Tsimaratou K, Evangelou K, Fernandez Marcos PJ, Zoumpourlis V, Trougakos IP, Kletsas D, Bartek J, Serrano M, Gorgoulis VG. Specific lipofuscin staining as a novel biomarker to detect replicative and stress-induced senescence. A method applicable in cryo-preserved and archival tissues. Aging (Albany NY). 2013;5: 37-50.

[127] Merlo S, Nakayama AB, Brusco J, Rossi MA, Carlotti CG Jr, Moreira JE. Lipofuscin granules in the epileptic human temporal neocortex with age. Ultrastruct Pathol. 2015;39:378-384. DOI:10.3109/01913123.2015.1043416.

[128] Giaccone G, Orsi L, Cupidi C, Tagliavini F. Lipofuscin hypothesis of Alzheimer's disease. Dement Geriatr Cogn Dis Extra. 2012;1: 292-296. DOI:10.1159/000329544.

[129] Seong SY, Matzinger P. Hydrophobicity: an ancient damage-associated molecular pattern that initiates innate immune responses. Nat Rev Immunol. 2004; 4: 469-478. DOI:10.1038/nri1372. 
[130] Brunk UT, Terman A. Lipofuscin: mechanisms of age-related accumulation and influence on cell function, Free Radic Biol Med. 2002;33: 611-619. DOI:10.1016/S08915849(02)00959-0.

[131] Naylor RM, Baker DJ, van Deursen JM. Senescent cells: a novel therapeutic target for aging and age-related diseases. Clin Pharmacol Ther. 2013;93:105-116. DOI:10.1038/ clpt.2012.193.

[132] Campisi J, d'Adda di Fagagna F. Cellular senescence: when bad things happen to good cells. Nat. Rev. Mol. Cell Biol. 2007;8:729-740. DOI:10.1038/nrm2233.

[133] Chinta SJ, Lieu CA, Demaria M, Laberge RM, Campisi J, Andersen JK. Environmental stress, ageing and glial cell senescence: a novel mechanistic link to Parkinson's disease? J. Intern. Med. 2013;273:429-436. DOI:10.1111/joim.12029.

[134] Bhat R, Crowe EP, Bitto A, Moh M, Katsetos CD, Garcia FU, Johnson FB, Trojanowski JQ, Sell C, Torres C. Astrocyte senescence as a component of Alzheimer's disease. PLoS One. 2012;7:1-10. DOI:10.1371/journal.pone.0045069.

[135] Wu Z, Nakanishi H. Lessons from microglia aging for the link between inflammatory bone disorders and Alzheimer's disease. J Immunol Res. 2015; 471342. DOI: $10.1155 / 2015 / 471342$.

[136] Bilbo SD, Schwarz JM. Early-life programming of later-life brain and behavior: a critical role for the immune system. Front Behav Neurosci. 2009; 3:14. DOI:10.3389/neuro. 08.014.2009.

[137] Hsiao EY, McBride SW, Hsien S, Sharon G, Hyde ER, McCue T, Codelli JA, Chow J, Reisman SE, Petrosino JF, Patterson PH, Mazmanian SK. Microbiota modulate behavioral and physiological abnormalities associated with neurodevelopmental disorders. Cell. 2013;155:1451-1463. DOI:10.1016/j.cell.2013.11.024.

[138] Meyer U, Nyffeler M, Engler A, Urwyler A, Schedlowski M, Knuesel I, Yee BK, Feldon J. The time of prenatal immune challenge determines the specificity of inflammationmediated brain and behavioral pathology. J Neurosci. 20056;26: 4752-4762.

[139] Cani PD, Amar J, Iglesias MA, Poggi M, Knauf C, Bastelica D, Neyrinck AM, Fava F, Tuohy KM, Chabo C, Waget A, Delmée E, Cousin B, Sulpice T, Chamontin B, Ferrières J, Tanti JF, Gibson GR, Casteilla L, Delzenne NM, Alessi MC, Burcelin R. Metabolic endotoxemia initiates obesity and insulin resistance. Diabetes. 2007;56: 1761-1772. DOI: 10.2337/db06-1491.P.D.C.

[140] Kim K, Jeong JJ, Yoo SY, Kim DH. Gut microbiota lipopolysaccharide accelerates inflamm-aging in mice. BMC Microbiol. 2016;16:16-19. DOI: 10.1186/s12866-016-06257.

[141] van Deursen JM. The role of senescent cells in ageing. Nature. 2014;509:439-446. DOI: 10.1038/nature13193. 
[142] Vicente R, Mausset-Bonnefont AL, Jorgensen C, Louis-Plence P, Brondello JM. Cellular senescence impact on immune cell fate and function. Aging Cell. DOI: 10.1111/acel. 12455.

[143] Streit WJ, Xue QS. Alzheimer's disease, neuroprotection, and CNS immunosenescence. Front Pharmacol. 2012;3 138. DOI:10.3389/fphar.2012.00138.

[144] von Bernhardi R, Eugenín-von Bernhardi, Eugenín J. Microglial cell dysregulation in brain aging and neurodegeneration, Front Aging Neurosci. 2015;7:124. DOI:10.3389/ fnagi.2015.00124.

[145] Ke HC, Huang HJ, Liang KC, Hsieh-Li HM. Selective improvement of cognitive function in adult and aged APP/PS1 transgenic mice by continuous non-shock treadmill exercise. Brain Res. 2011;1403:1-11. DOI: 10.1016/j.brainres.2011.05.056

[146] Morgan T. Wong A. Finch C. Anti-inflammatory mechanisms of dietary restriction in slowing aging processes, in: N.Y. Mobbs C.V. (New York (Ed.), Mech. Diet. Restrict. Aging Dis. 2007: pp. 83-97. DOI:10.1159/000096557.

[147] Ke HC, Huang HJ, Liang KC, Hsieh-Li HM. Selective improvement of cognitive function in adult and aged APP/PS1 transgenic mice by continuous non-shock treadmill exercise. Brain Res. 2011;1403:1-11. DOI: 10.1016/j.brainres.2011.05.056.

[148] Golde TE, Miller VM. Proteinopathy-induced neuronal senescence: a hypothesis for brain failure in Alzheimer's and other neurodegenerative diseases. Alzheimers Res Ther. 2009;1(2): 5. DOI:10.1186/alzrt5.

[149] Wisniewski HM, Moretz RC, Lossinsky AS. Evidence for induction of localized amyloid deposits and neuritic plaques by an infectious agent. Ann Neurol. 1981;10:517522. DOI:10.1002/ana.410100605.

[150] Honma T, Hatta K, Hitomi Y, Kambayashi Y, Hibino Y, Konoshita T, Nakamura H. Increased systemic inflammatory interleukin-1 and interleukin-6 during agitation as predictors of Alzheimer's disease. Int J Geriatr Psychiatry. 2013;28:233-241. DOI: 10.1002/gps.3816.

[151] Wisniewski T, Ghiso J, Frangione B. Alzheimer's disease and soluble A beta. Neurobiol Aging. 1994;15:143-52. DOI:10.1016/0197-4580(94)90105-8.

[152] Devi L, Ohno M. Cognitive benefits of memantine in Alzheimer's 5XFAD model mice decline during advanced disease stages. Pharmacol Biochem Behav. 2016;144: 60-66. DOI:10.1016/j.pbb.2016.03.002.

[153] Hardy J, Selkoe DJ. The amyloid hypothesis of Alzheimer's disease: progress and problems on the road to therapeutics. Science. 2002;297: 353-356. DOI:10.1126/science. 1072994.

[154] Nilsson P, Saito T, Saido TC. New mouse model of Alzheimer's. ACS Chem Neurosci. 2014;5: 499-502. DOI:10.1021/cn500105p. 
[155] Kuperstein I, Broersen K, Benilova I, Rozenski J, Jonckheere W, Debulpaep M, Vandersteen A, Segers-Nolten I, Van Der Werf K, Subramaniam V, Braeken D, Callewaert G, Bartic C, D’Hooge R, Martins IC, Rousseau F, Schymkowitz J, De Strooper B. Neurotoxicity of Alzheimer's disease $A \beta$ peptides is induced by small changes in the A 342 to A 340 ratio. EMBO J. 2010. 29: 3408-3420. DOI:10.1038/emboj.2010.211.

[156] Zhou Y, Liu L, Hao Y. Detection of $A \beta$ monomers and oligomers: early diagnosis of Alzheimer's disease. Chem Asian J. 2016;11:805-817. DOI: 10.1002/asia.201501355.

[157] Szaruga M, Veugelen S, Benurwar M, Lismont S, Sepulveda-Falla D, Lleo A, Ryan NS, Lashley T, Fox NC, Murayama S, Gijsen H, De Strooper B, Chávez-Gutiérrez L. Qualitative changes in human $\gamma$-secretase underlie familial Alzheimer's disease. J Exp Med. 2015. 212(12):2003-2013. DOI:10.1084/jem.20150892.

[158] Herrup K. The case for rejecting the amyloid cascade hypothesis. Nat Neurosci. 2015. 18(6):794-799. DOI: 10.1038/nn.4017.

[159] Ashe KH, Zahs KR. Review probing the biology of Alzheimer 's disease in mice. Neuron. 2010. 66:631-645. DOI:10.1016/j.neuron.2010.04.031.

[160] Manzano S, González J, Marcos A, Payno M, Villanueva C, Matías-Guiu J. Experimental models in Alzheimer's disease. Neurologia. 2009;24:255-252.

[161] Duyckaerts C, Potier MC, Delatour B. Alzheimer disease models and human neuropathology: similarities and differences. Acta Neuropathol. 2007;115:5-38. DOI:10.1007/ s00401-007-0312-8.

[162] Sarasa M. Experimental models for Alzheimer's disease research. Rev Neurol. 2006;42:297-301.

[163] Janelsins MC, Mastrangelo MA, Park KM, Sudol KL, Narrow WC, Oddo S, LaFerla FM, Callahan LM, Federoff HJ, Bowers WJ. Chronic neuron-specific tumor necrosis factoralpha expression enhances the local inflammatory environment ultimately leading to neuronal death in 3xTg-AD mice. Am. J. Pathol. 2008;173:1768-1782. DOI:10.2353/ ajpath.2008.080528.

[164] Mufson EJ, Ginsberg SD, Ikonomovic MD, DeKosky ST. Human cholinergic basal forebrain: chemoanatomy and neurologic dysfunction. J Chem Neuroanat. 2003;26:233-242. DOI:10.1016/S0891-0618(03)00068-1.

[165] Geula C, Nagykery N, Nicholas A, Wu CK. Cholinergic neuronal and axonal abnormalities are present early in aging and in Alzheimer disease. J Neuropathol Exp Neurol. 2008;67:309-318. DOI:10.1097/NEN.0b013e31816a1df3.

[166] Ikonomovic MD, Klunk WE, Abrahamson EE, Wuu J, Mathis CA, Scheff SW, Mufson EJ, DeKosky ST. Precuneus amyloid burden is associated with reduced cholinergic activity in Alzheimer disease. Neurology. 2011;77:39-47. DOI:10.1212/WNL. 0b013e3182231419. 
[167] Orta-Salazar E, Aguilar-Vázquez A, Martínez-Coria H, Luquín-De Anda S, RiveraCervantes S, Beas-Zarate C, Feria-Velasco A, Diaz Cintra S. REST/NRSF-induced changes of ChAT protein expression in the neocortex and hippocampus of the 3xTgAD mouse model for Alzheimer's disease. Life Sci. 2014;116:83-89. DOI: 10.1016 / j.lfs. 2014.09.013

[168] Boissie F, Faucheux B, Agid Y, Hirsch EC. Choline acetyltransferase mRNA expression in the striatal neurons of patients with Alzheimer 's disease. Neurosci Lett. 1997;225:169-172.

[169] Orta-Salazar E, Feria-Velasco A, Medina-Aguirre G, Morphological analysis of the hippocampal region associated with an innate behaviour task in the transgenic mouse model (3xTg-AD) for Alzheimer disease. Neurologia. 2013;28:497-502. DOI: 10.1016/ j.nrl.2013.01.014.

[170] Ruehl WW, Bruyette DS, DePaoli A, Cotman CW, Head E, Milgram NW, Cummings BJ. Canine cognitive dysfunction as a model for human age-related cognitive decline, dementia and Alzheimer's disease: clinical presentation, cognitive testing, pathology and response to 1-deprenyl therapy. Prog Brain Res. 1995;106:217-225.

[171] Ardiles AO, Tapia-Rojas CC, Mandal M, Alexandre F, Kirkwood A, Inestrosa NC, Palacios AG. Postsynaptic dysfunction is associated with spatial and object recognition memory loss in a natural model of Alzheimer's disease. Proc Natl Acad Sci USA. 2012;109:13835-13840. DOI:10.1073/pnas.1201209109.

[172] Sparks DL, Schreurs BG. Trace amounts of copper in water induce beta-amyloid plaques and learning deficits in a rabbit model of Alzheimers's disease. Proc Natl Acad Sci USA. 2003;100:11065-11069.

[173] Miklossy J, McGeer PL. Common mechanisms involved in Alzheimer's disease and type 2 diabetes: a key role of chronic bacterial infection and inflammation. Aging (Albany NY) 2016; 8:575-88. DOI: 10.18632/aging.100921..

[174] Duff, F. Suleman F. Transgenic mouse models of Alzheimer's disease: how useful have they been for therapeutic development? Brief Funct Genomic Proteomic. 2004;3: 47-59. http://www.ncbi.nlm.nih.gov/entrez/query.fcgi?cmd=Retrieve\&db=PubMed\&dopt=Citation\&list_uids=15163359. 